Revista de Derecho de la Pontificia Universidad Católica de Valparaíso XXXV (Valparaíso, Chile, 2010, 20 Semestre)

[pp. 245 - 286]

\title{
LA SOBERANÍA POPULAR COMO FUNDAMENTO DEL ORDEN ESTATAL Y COMO PRINCIPIO CONSTITUCIONAL ${ }^{*}$
}

["Popular Sovereignty as the Foundation of the State Order and as Constitutional Principle"]

\author{
Pablo Marshall BarberáN** \\ Universidad Austral de Chile
}

\begin{abstract}
RESUMEN
El presente trabajo busca exponer el origen y fundamento del principio de la soberanía popular, su rol dentro de la teoría constitucional contemporánea y el significado y alcance que tiene su consagración constitucional en Chile. Para ello, se propone analizar cuál es el rol de la soberanía popular en cada una de las dimensiones en que es habitualmente usado: teoría política, teoría constitucional y dogmática, y detectar cuál es la relación entre dichas dimensiones.

Palabras Clave: Constitución - Soberanía popular - Pueblo - Poder constituyente.
\end{abstract}

\begin{abstract}
This work aims at presenting the origin and the basis of the principle of popular sovereignty, its role within the contemporaneous theory of the constitution and the meaning and extent that its constitutional enshrining has in Chile. To do this, the role of popular sovereignty in each of the dimensions it is commonly used is analyzed: political theory, constitutional and dogmatic theory, as well as detecting the relationship among said dimensions.

KeYwords: Constitution - Popular sovereignty - People - Constituent power.
\end{abstract}

* Este trabajo se enmarca dentro de una investigación financiada por la Dirección de Investigación y Desarrollo de la Universidad Austral de Chile (Proyecto S-200906).

** Profesor de Derecho constitucional de la Facultad de Ciencias Jurídicas y Sociales de la Universidad Austral de Chile. Dirección postal: Facultad de Ciencias Jurídicas y Sociales, Universidad Austral, Campus Isla Teja, Valdivia, Chile. Correo electrónico: pmarshall@uach.cl 


\section{INTRODUCCIÓN}

Una pregunta que ha ocupado un lugar importante entre las preocupaciones de filósofos, políticos y abogados por siglos, es la de cuál es el fundamento del ejercicio del poder político por parte del Estado. Carrè de Malberg sugirió que la respuesta a esta pregunta debe darse en dos niveles. En el nivel estrictamente jurídico, los órganos estatales obtienen la calidad para actuar a nombre del Estado del propio Derecho creado por el Estado; en última instancia de la norma jurídica suprema. La respuesta jurídica es, por tanto, circular. La segunda respuesta, puede encontrarse, según Carrè, en un nivel más profundo del significado de la constitución. En este caso, se trata de determinar de dónde viene la legitimidad del poder estatal, si es que no puede venir del propio Derecho creado en virtud de ese mismo poder. La pregunta por la legitimidad del orden jurídico estatal, en términos de Carrè de Malberg busca determinar en quién reside la soberanía y, por tanto, quién es el titular del poder constituyente ${ }^{1}$.

Siguiendo de cerca la sugerencia de Carrè, puede sostenerse que la pregunta por la soberanía es posible de abordar desde tres perspectivas, todas ellas pertinentes para el estudio de la constitución. Dichas perspectivas son la filosofía política, la teoría constitucional y, por último, la dogmática constitucional ${ }^{2}$.

Desde la primera perspectiva -la filosófica -, la pregunta por la soberanía pasa por determinar si el monopolio de la violencia que el Estado moderno reclama puede ser justificado por una expresión de voluntad del pueblo sobre el cual dicho poder se detenta. Desde esta perspectiva, la teoría de la soberanía ocupa un lugar privilegiado entre las teorías que intentan explicar la forma en la cual se expresa el consentimiento de los individuos en someterse al poder del Estado. Ello es así, no por su rigor filosófico y su capacidad de contestar a las objeciones que se le puedan formular, sino por que coincide con la comprensión común de los ciudadanos acerca de lo que hacen y cómo funcionan las instituciones fundamentales de nuestra organización política, como la constitución y la democracia.

Desde la segunda perspectiva -la teórica-, la pregunta por la soberanía se dirige a aclarar el fundamento que tiene el orden estatal que está encabezado por la constitución. La soberanía es una respuesta política -no moral- a la pregunta acerca de por qué debemos obedecer el Derecho. Una pregunta a la que el Derecho sólo puede contestar con una respuesta circular. La nece-

\footnotetext{
${ }^{1}$ Carré de Malberg, Raymond, Teoría general del Estado (México, Fondo de Cultura Económica, 1948), pp. 867-871.

${ }^{2}$ Cft. Böckenförde, E. W., Estudios sobre el Estado de Derecho y la democracia (Madrid, Trotta, 2002), pp. 160-161.
} 
sidad de encontrar un fundamento meta-jurídico a la validez del Derecho, tiende un puente entre el fundamento filosófico de la legitimidad del Estado, construido en términos puramente especulativos, la realidad política sobre la cual se erige el fenómeno del dominio estatal sobre los individuos y, en último término, la afirmación de la validez del Derecho. La respuesta de la soberanía popular a esta pregunta se articula como una imputación al pueblo de un poder pre-jurídico para fundar mediante un acto de voluntad el orden estatal que desea.

Finalmente, desde la perspectiva de la dogmática constitucional, la cuestión decisiva es abordar la interrogante acerca del significado y alcance que tiene la consagración del principio de la soberanía popular en el texto de la constitución. En términos particulares, qué significa que la Constitución Politica de la República de Chile establezca en su artículo 5 que la soberanía reside en la nación y qué alcances puede tener dicho establecimiento para el ejercicio de las potestades estatales. Por ejemplo, si tiene alguna incumbencia en el ejercicio del control de constitucionalidad de la ley que los ministros del Tribunal Constitucional deben hacer; o, por el contrario, si sólo cumple -parafraseando a Jaime Guzmán- una función pedagógica.

El problema de estas tres perspectivas es que no están claramente separadas. Eso marca el primer y más demandante objetivo de este trabajo. Por supuesto que su tratamiento aislado no puede ser fructífero. En la medida que existe influencia determinante entre los niveles -especialmente entre la teoría constitucional y la dogmática- la explicación debe ser complementaria y relacionar las perspectivas, procurando instalar a cada una en el lugar que resulte adecuado para poder entenderlas en sus propios términos.

El trabajo además tiene un segundo objetivo. Busca exponer el origen y fundamento del principio de la soberanía popular, su rol dentro de la teoría constitucional contemporánea y el significado y alcance que tiene su consagración constitucional en Chile. De cara a ese objetivo, la exposición que sigue tiene una estructura que se compone de cuatro partes. La primera intenta presentar el origen del concepto de soberanía y el problema en relación a su titularidad. El objetivo de esta parte es la de delimitar la dimensión filosófica de la soberanía de su dimensión teórica constitucional. Luego, la segunda parte, revisará la teoría del poder constituyente, íntimamente ligada a la teoría de la soberanía, pero que aborda el problema de la constitución del Estado desde una perspectiva estrictamente teórica. La tercera parte abordará las críticas que se han dirigido a la teoría de la soberanía y del poder constituyente en el nivel de la teoría constitucional. Por último, en la cuarta parte del trabajo, se hace un análisis de la disposición del artículo 5 de la Constitución Política, como una referencia a la teoría de la soberanía y del poder constituyente. Esta parte se desenvuelve en el nivel de la dogmática constitucional. 


\section{EL ORIGEN, EL CONCEPTO Y EL TITULAR DE LA SOBERANÍA}

\section{Los origenes del concepto de soberania.}

Si es que pretende entendérselo como la justificación o el título en virtud del cual los gobernantes ejercen el poder del Estado frente a los gobernados, por supuesto que el fenómeno del que la soberanía da cuenta no es nuevo y puede ser rastreado hasta la filosofía política clásica. Sin embargo, la opinión mayoritaria sostiene que la soberanía es un concepto moderno. En sus estrictos términos la acuñación del concepto de soberanía es atribuida indubitadamente a Jean Bodin, quien formuló la noción de soberanía de la forma en que actualmente conserva vigencia ${ }^{3}$.

Bodin presentó la idea de la soberanía como una solución para el problema de la guerra civil francesa causada por razones religiosas. La idea de soberanía estaba dirigida a fundar la paz en el interior de las fronteras nacionales. La soberanía contextualizada en sus circunstancias de origen, implicaba que la paz religiosa sólo se podía lograr si el rey tenía la suficiente fuerza para imponer la tolerancia religiosa a todas las partes en disputa. La soberanía implicaba la solución de los conflictos entre particulares o grupos por medio del monopolio de la fuerza en unas solas manos. Ni el partido católico ni el protestante podrían hacer uso de la fuerza sin al mismo tiempo estar realizando una agresión al poder real, esto es, cuestionando su soberanía ${ }^{4}$.

El principio de la soberanía del rey, así presentado, parece fundar un reemplazo del Estado feudal, con varios polos de poder, por un nuevo Estado, con un solo polo de poder central. ¿Cómo funcionaba el argumento de Bodin? Partiendo de la base que el poder de los señores dependía del buen y antiguo Derecho, el reemplazo del poder de los señores por el poder real requería de un fundamento que fuera más allá de ese Derecho consuetudinario medieval; requería un poder que no tuviera que limitarse al Derecho: un poder que pudiese violar el Derecho. Es así como el principio de la soberanía se identificó como el ejercicio del poder centralizadamente por parte del rey de forma "absoluta y perpetua".

Que el poder del rey fuera perpetuo significaba que no estaba sujeto a un periodo determinado, sino que era ejercido de por vida. Que fuera absoluto,

${ }^{3}$ Por todos: KRIELE, Martin, Introducción a la teoria del Estado: Fundamentos históricos de la legitimidad del Estado constitucional democrático (Buenos Aires, Depalma, 1980), pp. 53 ss. Los antecedentes medievales del concepto de soberanía se pueden retrotraer hasta el imperio romano tardío. Así, Bermejo, José Luis, Orígenes medievales en la idea de soberanía, en Revista de Estudios Politicos, 200-201 (1975); y WyducKEL, Dieter, La soberania en la Historia de la dogmática alemana, en Fundamentos, 1 (1998).

${ }^{4}$ Kriele, Martin, cit. (n. 3). 
implicaba que el rey estaba exento de la obligación de obedecer las leyes. Por supuesto que el rey no estaba limitado por las leyes, si es que podía cambiar su contenido por el ejercicio de su voluntad legisladora. Sin embargo, contra la opinión general, en su origen, la soberanía del rey no se presentó como un poder exento de límites, y de esta manera absoluto e ilimitado no aparecen como sinónimos 5 .

Bodin comprendía los límites de la soberanía vinculándolos, en primer lugar, al Derecho natural y divino; en segundo lugar, a los tratados celebrados con otros Estados; finalmente, el rey debía respetar las leyes involucradas en la constitución del gobierno monárquico, esto es, las leyes de la corona. En ese sentido, la soberanía estaba bien limitada; no era un poder sin límites. La característica clave que distinguía a la soberanía era la de no estar limitada por los antiguos y buenos derechos feudales, lo que era sensato si se tiene en cuenta que lo que impedía poner fin a la guerra religiosa era, justamente, el Derecho; en concreto los derechos de guerra de cada uno de los partidos en pugna. Lo que interesa destacar es que la soberanía, para Bodin, no confería un poder ilimitado ${ }^{6}$.

En los hechos, la sociedad feudal dio paso, sólo paulatinamente a la incorporación del poder centralizado del rey. En tiempos de la revolución francesa todavía pueden verse vestigios importantes del poder aristocrático que era ejercido a costas del poder regio 7 . El principio de la soberanía competía y coexistía con la estructura feudal ${ }^{8}$. Sin embargo, también en los hechos, la teoría de la soberanía tuvo un éxito sin precedentes. Por supuesto que no mediante el ejercicio central e ilimitado del poder por parte del rey, sino mediante la posibilidad del rey de suspender los derechos de los señores a hacer la guerra y así lograr cierta paz religiosa. El éxito de la soberanía como argumento para la pacificación religiosa se debió en gran medida a su capacidad persuasiva? Por supuesto que al final del día la pacificación se logró mediante la política y la guerra. Sin embargo, la teoría de la soberanía envolvió de legitimidad a la

${ }^{5}$ Bоввіо, Norberto, La teoría de las formas de gobierno en la Historia del pensamiento político: Año académico 1975-1976 (México, Fondo de Cultura Económica, 2001), p. 81.

${ }^{6}$ KRIELE, Martin, cit. (n. 3), pp. 53-80. Una lectura similar se puede encontrar en Fioravanti, Mauricio, Estado y constitución, en Fioravanti, Mauricio (editor), El Estado moderno en Europa. Instituciones y Derecho (ciudad Trotta, 2004).

${ }^{7}$ Toceueville, Alexis de, El Antiguo régimen y la Revolución (México, Fondo de Cultura Económica, 1996), pp. 166 ss.

${ }^{8}$ Fioravanti, Mauricio, cit. (n. 6).

${ }^{9}$ KrIELE, Martin, cit. (n. 3), pp. 74 ss.: "Esta teoría no tenía una función jurídica, sino político-programática. Los reyes tenían, en parte, competencia muy amplia, pero esta competencia estaba legitimada, en el mundo de las ideas medievales, por el Derecho". 
imposición forzada de los edictos de tolerancia por parte del rey y encaminó a Francia al proceso centralizador que sería denominado estereotípicamente como monarquía absoluta.

\section{La soberanía y el liberalismo.}

La pérdida de prestigio del concepto de soberanía, por su identificación con la monarquía absoluta francesa llevó, por un lado, a que el liberalismo se autocomprendiera como una reacción frente a la soberanía ${ }^{10}$. Esto es entendible si se tiene en frente un concepto de soberanía que se identifica con el concepto de Estado absoluto: la soberanía como el poder ilimitado de quién no está vinculado por el Derecho ${ }^{11}$.

Si bien esta versión de la soberanía no puede encontrarse en la obra de Bodin, puede encontrarse en la obra de otro representante de gran pedigrí de la teoría de la soberanía, que abogaba por la concentración del poder político en unas solas manos en busca del término de la guerra civil religiosa. Sin embargo, para Hobbes, a diferencia de Bodin, la soberanía del rey era un poder absoluto y sin límite. Bobbio escribe al respecto: "Aunque pueda parecer que un atributo como "absoluto" no permita un superlativo, no es descabellado decir que el poder soberano de Hobbes es más absoluto que el de Bodino. Como hemos visto, para Bodino el poder del soberano, aun siendo absoluto, en cuanto no está limitado por las leyes positivas, reconoce límites [...]. Frente a la índole absoluta del poder soberano como la concibe Hobbes, ambos límites desaparecen"12.

Hobbes consideraba que el poder del Estado debía ser ejercido sin límites, de lo contrario nos encontraríamos ante el fin del Estado y ante el regreso al estado de guerra de todos contra todos. El contrato social de Hobbes, como medio para fundar el Estado, implicaba la renuncia, por parte de cada uno de los individuos que lo suscribían, al ejercicio de medios de violencia. Se confiaban de esta manera al único, central e ilimitado poder estatal que garantizaría, como contrapartida, la seguridad de los individuos tanto frente a sus vecinos como frente a pueblos extranjeros. Los individuos no se reservaban nada; lo entregaban todo por medio del contrato. Si los individuos

\footnotetext{
${ }^{10}$ Se ha señalado que el lugar secundario que ha alcanzado el concepto de soberanía se debe a que despierta anticuerpos y antipatías. Ello puede encontrar su explicación en nuestros días en: $i$ ) el actual proceso de globalización y sus efectos corrosivos de la soberanía estatal; ii) la tensión entre el poder soberano y la protección de los derechos humanos universales; y iii) el redescubrimiento del cosmopolitanismo. Así Kalyvas, Andreas, Soberania popular, democracia y el poder constituyente, en Política y Gobierno,12 (2005), p. 92.

${ }^{11}$ Véase Carré de Malberg, Raymond, cit. (n. 1), p. 873.

${ }^{12}$ Boвbio, Norberto, cit. (n. 5), p. 96.
} 
nada tenían, y el Estado lo tenía todo, no es sorprendente descubrir que el único límite que puede encontrarse en la obra de Hobbes, para el poder del soberano, es el de respetar la vida de sus propios súbditos ${ }^{13}$.

Cuando se contrasta con Bodin, parece claro que los límites que el liberalismo se propone constituir frente al poder arbitrario del Estado tienen ésta última concepción de la soberanía en consideración. En ese sentido, todas las instituciones que el liberalismo idea para la limitación de la arbitrariedad y el abuso del poder del Estado, están pensadas teniendo como objeto de limitación a un Estado que cuenta con un poder ilimitado: el principio de separación de poderes, el establecimiento de los derechos fundamentales, y en general, la fórmula de crear mediante el Derecho un sistema de control del poder del Estado.

\section{La soberanía como poder de excepción.}

Si se observa detenidamente la propuesta de la soberanía de Bodin, puede deducirse lo siguiente: $i$ ) la teoría fue ideada con la expresa finalidad de dar una solución al problema excepcional de la guerra religiosa; ii) la solución consistía en entregar un poder exclusivo al rey, un poder mediante el cual el rey podía imponer por la fuerza la paz y la tolerancia; iii) ese poder no consistía en un poder ilimitado, porque debía respetar el Derecho natural y divino, el Derecho constitucional monárquico y el Derecho internacional (y en gran medida, por prudencia y su débil capacidad de hacer cumplir sus ordenes frente a los señores, el Derecho que regulaba las actividades feudales y privadas); $i v$ ) era un poder que confería al rey la posibilidad de actuar sin sujetarse al Derecho establecido. Especialmente lo habilitaba a desconocer el derecho que tenían los partidos católico y "huguenot" para hacer la guerra. Esta última afirmación es de suma importancia, dado que el poder soberano no se ejerció más que de modo específico y excepcional. No acarreó la supresión de los antiguos derechos, sino más bien su suspensión paulatina y parcelada. En definitiva, puede sostenerse que la tesis de Bodin consistía en que la soberanía era el título por medio del cual el rey podía no sujetarse al Derecho; no era un poder ilimitado. Esta afirmación tiene una conexión muy estrecha con la afirmación de Schmitt de que la soberanía es el poder para decidir sobre el estado de excepción ${ }^{14}$. Para ambos, la soberanía consistía en una instancia para eludir el cumplimiento del Derecho.

${ }^{13}$ Hoвbes, Thomas, Leviatan o la materia, forma y poder de una república, eclesiástica y civil (México, Fondo de Cultura Económica, 1980), pp. 171 ss. Una comparación de la noción de soberanía en Hobbes y Bodin puede encontrarse Bоввіо, Norberto, cit. (n. 5), pp. 95 ss.

${ }^{14}$ Schmitt, Carl, Teología politica 1, en Orestes, Héctor (editor), Carl Schmitt, teólogo de la politica (México, Fondo de Cultura Económica, 2001), p. 23. 
El estado de excepción, para Schmitt, se define por oposición al estado de normalidad. El estado de normalidad, en términos de un orden estatal, es el momento donde el Derecho tiene plena vigencia y aplicación: es el momento donde la infracción de una norma acarrea la imputación de una sanción. En términos de la vida constitucional de un Estado, la normalidad es aquel momento en el que la constitución tiene plena aplicación: donde los órganos competentes para actuar deben respetar procedimientos, sin cuya concurrencia sus actos serán anulados.

Pero la normalidad sólo puede definirse por referencia a la excepción. La excepción es el momento en que el Derecho se suspende (o en que la constitución se suspende), ya sea por un caso de necesidad extrema o de peligro para la existencia del Estado. Son los momentos en que la infracción de una norma no acarrea necesariamente una sanción y en que los órganos del Estado no actúan mediante procedimientos preestablecidos. Los supuestos de la excepción, no pueden, desde luego, estar contenidos en el propio Derecho, si es que pretenden ser excepciones al Derecho mismo ${ }^{15}$.

El orden estatal ordinariamente procesa los problemas jurídicos como normales y les asigna las soluciones previstas por el Derecho para la normalidad. El soberano sin embargo, puede determinar cuándo dicha obligación se suprime por la existencia de una situación excepcional, como lo era la amenaza de la guerra religiosa en Francia ${ }^{16}$. El concepto de soberanía de Schmitt permite entender qué significa que el rey de Francia sea soberano. Pero también permite entender qué significa que haya un soberano en el Estado moderno. La existencia de un soberano permite comprender que el orden jurídico estatal sea posible.

En la medida que el soberano se sitúa fuera del orden jurídico, por el cual no puede ser comprendido, la tendencia del orden estatal será a negar su existencia. Sin embargo, negar la existencia del soberano es lo mismo que negar la posibilidad de la excepción. Si se niega la existencia de la distinción normalidad-excepción se niega parte importante de nuestra historia institucional y política, y se niega la posibilidad de una fundamentación trascendente del orden estatal vigente.

Sólo si es posible que el Derecho no esté vigente es que puede afirmarse que el Derecho está vigente. Si es posible que el Derecho sea suspendido en

${ }^{15}$ De esta forma, los supuestos de los estados de excepción contemplados en los artículos 35 a 45 de la Constitución Política no pueden entenderse como la incorporación de los supuestos del ejercicio de la soberanía al orden constitucional, sino como un intento por redefinir la situación de normalidad constitucional, contemplando otros supuestos. Ello sin duda puede restringir las situaciones extraordinarias para la constitución.

${ }^{16}$ Schmitt, Carl, cit. (n. 14), p. 24. 
un momento excepcional, esa suspensión no puede estar entregada por el Derecho a nadie, dado que el Derecho no estaría en serio suspendido, sólo estaría, usando una expresión extraña, recogido ${ }^{17}$. En ese sentido, la autoconciencia de la suspensión del Derecho no es algo posible: el Derecho no puede ser reflexivo. Cuando nos encontramos en un estado de excepción, el Derecho es real y totalmente suspendido, y es en ese momento que podemos identificar a quién tiene el poder para realizar tal suspensión. Si el soberano tiene el poder para suspender el Derecho, tiene al mismo tiempo, el poder para mantenerlo vigente. El soberano es, por tanto, no quien tiene la libertad de violar el Derecho vigente impunemente, como parece observar el liberalismo respecto del la soberanía absoluta, sino -y esta es la nota esencial de la soberanía según Schmitt- quien tiene el poder de declarar que el Derecho está suspendido y, por tanto, no es susceptible de ser violado o seguido ${ }^{18}$.

En el pensamiento de Schmitt, la soberanía es concebida, con independencia de su titularidad, como un poder para suspender el Derecho. Puede observarse que el rey puede ser soberano si cuenta con ese poder. Sin embargo, en cada época y sociedad, el soberano puede ser distinto del rey. Hoy en día existe un consenso, o por lo menos así hace pensar la Constitución Politica de Chile, acerca de que el soberano es el pueblo. ¿Qué implica aquello? Afirma que es el pueblo quien tiene el poder de suspender el Derecho y la constitución.

Antes de abordar el problema de la titularidad de la soberanía debe llevarse a cabo una aclaración sobre la tesis de Schmitt acerca de la soberanía. Como se puede observar, de lo que ha ocupado este trabajo hasta ahora es del concepto de soberanía. Ello se ha realizado mediante la contraposición de dos concepciones, Hobbes y Bodin. Se intentó explicar que la diferencia fundamental entre dichas concepciones radica en su limitación. También se ha intentado explicar que, en los hechos, la soberanía no justificó más que la intervención excepcional del rey en el extendido régimen de derechos feudales. Ese carácter no manifiesto permanentemente, parece ser el objeto de fascinación de Schmitt en su concepción de la soberanía. Existe una conexión estrecha entre Bodin y Schmitt especialmente a ese respecto. La soberanía sólo se manifestaba cuándo la necesidad lo requería. En cambio en Hobbes la soberanía estaba todo el tiempo expuesta y en constante ejercicio, lo que

\footnotetext{
${ }^{17}$ Como puede sostenerse que sucede en los estados de excepción constitucional.

${ }^{18}$ Sobre el concepto de soberanía de Schmitt y su relación con el Derecho, esclarecedor es el trabajo de Fernando Atria, recogido en Atria, Fernando, El Derecho y la contingencia de lo político, en Derecho y Humanidades, 11 (2005); Atria, Fernando, Legalismo, derechos y politica, en VV. AA., Derechos fundamentales Sela 2001 (Buenos Aires, Del Puerto, 2003); y Atria, Fernando, La soberanía y lo politico, en Derecho y Humanidades, 12 (2006).
} 
llevaba a confundir la soberanía con el poder del Estado. Esa confusión simplificadora, que será abordada más adelante, es la que pone en evidencia la obra de Schmitt en que la soberanía no está siempre manifestándose. La soberanía está oculta en períodos de normalidad y se manifiesta durante la excepción ${ }^{19}$.

\section{El pueblo como titular de la soberania.}

Bodin tenía en mente al rey como titular de la soberanía. No porque Bodin fuera un seguidor de la doctrina del Derecho divino para gobernar ${ }^{20}$. Lo que a Bodin le interesó fue que el Estado conservara su unidad y estabilidad, frente a la amenaza que significaba la guerra religiosa. Su inclinación por el rey como titular de la soberanía obedece a las circunstancias de hecho de su tiempo y al mejor perfil del rey para centralizar el poder frente a un gobierno aristocrático o de una asamblea.

Doscientos años después de la aparición de la obra de Bodin, la idea de soberanía estuvo nuevamente en el centro de atención. Sin embargo, está vez la problemática trataba acerca de quién debía ser el soberano. La propuesta democrática y revolucionaria desplazaba la soberanía desde el rey hasta el pueblo.

a) Origen y fundamento de la soberanía popular. La Revolución Francesa implementó de manera abierta las ideas de Rousseau sobre el fundamento del poder del Estado. Casi todos los revolucionarios con influencia eran sus asiduos lectores. La primera propuesta consistía en la siguiente afirmación fundamental, que marcó la constitución de 1791: el poder del Estado ya no estaría en manos del monarca por una decisión divina, sino por una decisión del pueblo. Durante la profundización de la revolución, la propuesta mutó a la siguiente: por una decisión del pueblo, el poder del Estado ya no estará en manos del monarca. La idea de la soberanía popular se consolidó, entonces, en los hechos.

\footnotetext{
${ }^{19}$ Las teorías de Bodin y de Hobbes - por razones estratégicas-, y las de los teóricos de la soberanía popular - por razones de justicia-, presentan dos aspectos: intentaban justificar la residencia de la soberanía en unas manos e intentaban determinar cuáles son los atributos de la soberanía. Schmitt, en cambio, pretendió una teoría científica, en el sentido que el atributo de la soberanía consistiera justamente en la herramienta para descubrir, en quién ésta reside. Schmitt no estaba comprometido con la soberanía popular como un principio normativo superior, ni tampoco con la soberanía del monarca. Concebía su labor simplemente como una labor de diagnostico: allí donde resida el poder de suspender el Derecho, reside también la soberanía.

${ }^{20}$ Sobre la relación de la doctrina del Derecho divino con la consolidación del Estado absoluto: Crossman, R. H. S., Biografía del Estado moderno (México, Fondo de Cultura Económica, 2000), pp. 44 ss; y PASSERIN D’Entrèves, Alessandro, La noción del Estado: Una introducción a la teoría politica (Barcelona, Ariel, 2001), pp. 215 ss.
} 
La fórmula filosófica para respaldar estas ideas estaba en el recurso al contrato social de Rousseau. Mediante el contrato social -en palabras de Carrè-, cada uno de los individuos, naturalmente libres e iguales, "consiente en la enajenación total de su persona a favor de la comunidad, en tanto que se subordina, él y su voluntad, a la suprema dirección de la voluntad general, la que se convierte así en soberana. Pero, por otra parte, cada miembro es admitido por todos los demás como parte indivisible del todo, y por consiguiente, la misma voluntad general no es sino una resultante de voluntades individuales [...]"21.

Sieyès alineó las ideas de Rousseau en un modelo que las compatibilizara con la vieja idea de soberanía. Para ello acuñó el concepto de nación, para identificar a la comunidad política en la que reside la soberanía.

La teoría de la soberanía nacional de Sieyès es una relectura de la tesis de la soberanía de Rousseau. Por un lado, limitando sus implicaciones individualistas, que hacían que la soberanía no residiera en el pueblo como comunidad sino en cada uno de los ciudadanos que conformaban el pueblo y, por otro, poniéndola en relación con el viejo concepto de soberanía del monarca. La tesis de la soberanía nacional, era una tesis principalmente negativa que intentaba privar al monarca de la soberanía, para afirmar la primacía de una asamblea. La idea central de la teoría era considerar a la nación como algo preexistente al Estado, y a éste como la forma en que la nación (sin forma) se organizaba ${ }^{22}$.

El contexto en el cual surge y se afirma la teoría de la soberanía popular es igual de importante que en el caso de la soberanía del monarca. Si bien la especulación filosófica acerca de la igualdad y la libertad natural de los seres humanos, había sido obra de los hombres de letras, especialmente de Locke y Rousseau, la revolución francesa permitió que dichas ideas fueran llevadas a la práctica ${ }^{23}$. En particular, el contexto en que se plantearon fue el de la conformación de los Estados Generales. Su más distinguido defensor fue Sieyès. Su argumentación apuntaba a que el rey concediera una mayor representatividad al Estado Llano, esto es, a quienes no formaban parte de los órdenes privilegiados. Si bien las peticiones del Estado Llano eran moderadas, los principios que las sustentaban expresaban un completo desacuerdo con el orden establecido. Esos principios son los que más tarde, durante el curso de la revolución, se implementarían radicalmente en la republica ${ }^{24}$.

${ }^{21}$ Carré de Malberg, Raymond, cit. (n. 1), p. 876.

${ }^{22}$ SIEYÈs, Emmanuel-Joseph, Escritos políticos (México, Fondo de Cultura Económica, 1993), pp. 156-61.

${ }^{23}$ Véase, sobre otros teóricos del poder constituyente como Locke, Madison, Paine y Lawson, las referencias en Kalyvas, Andreas, cit. (n. 10), p. 96

${ }^{24}$ SiEYÈs, Emmanuel-Joseph, cit. (n. 22), pp. 129-45. 
La idea principal de Sieyès es que no había razón para el establecimiento de órdenes privilegiados de personas. Dichos privilegios no se sustentaban en título legítimo alguno y es más, iban contra el Derecho natural. Si los individuos son libres e iguales y ellos se asocian libremente en la nación, ellos pasan a formar parte de una unidad mayor que actúa voluntariamente como una comunidad. No parece haber razón, de esta manera, para que la igualdad que ellos tenían naturalmente, desaparezca. El Derecho debe, por tanto, ser igual para todos quienes forman la nación y debe ir en interés de la nación misma; debe ir en el interés general y no cautelar intereses particulares. Por supuesto que será necesario instaurar un gobierno, sin embargo, ese gobierno será uno en que los ciudadanos que lo asuman sean representantes de la nación y no actúen sino en interés de ella. De esta manera, el poder del Estado derivaba de una decisión de la nación, y todos los órganos del Estado, incluido el rey, no eran más que sus representantes ${ }^{25}$.

Las ideas de Sieyès tiene como principal testimonio su consagración en la Declaración de Derechos del Hombre y del Ciudadano, que en su artículo $3^{\circ}$ sostiene: "El principio de toda soberanía reside esencialmente en la Nación. Ninguna corporación o estamento, ningún individuo puede ejercer autoridad que no emane expresamente de ella".

b) El pueblo como comunidad política. La atribución de la titularidad de la soberanía al pueblo o a la nación ha suscitado extensos debates. La utilización de los conceptos de pueblo o nación por parte de las constituciones sigue motivando interpretaciones diversas del significado de soberanía.

La relevancia de la distinción de la soberanía popular y la soberanía nacional es algo que puede ser atendido de dos maneras. La primera, es explicar la diferencia entre la lectura atomista de Rousseau y la teoría propuesta en el seno de la asamblea constituyente de 1789 , que hace residir la soberanía de manera indivisible en la nación, entendida ésta como una comunidad política anterior y superior al Estado. No parece ser una distinción tan interesante más allá de entender el origen del concepto ${ }^{26}$.

La segunda forma de entender la relevancia de la distinción es negándola. Tanto la soberanía popular como la soberanía nacional hacen referencia hoy en día, a un mismo fenómeno, esto es, a la soberanía de la comunidad política. Ello puede aclararse si se toman en cuenta: $i$ ) la confusa utilización de los términos pueblo y nación en la literatura; y ii) el hecho de que las constituciones de los Estados modernos establezcan el principio de la sobe-

${ }^{25}$ SIEYÈs, Emmanuel-Joseph, cit. (n. 22), pp. 155-9.

${ }^{26}$ Cft. Sieyès, Emmanuel-Joseph, cit. (n. 22), pp. 155 ss.; y Rousseau, JeanJacques, Contrato social (Madrid, EspasaCalpe, 1921), pp. 45 ss. Sobre ellos: VARELA Su ANZEs, Joaquín, Algunas reflexiones sobre la soberanía popular en la constitución española, en Revista Española de Derecho Constitucional, 36 (1992), pp. 74-8 
ranía popular y nacional de manera indistinta, aludiendo a la soberanía de la comunidad política ${ }^{27}$. Ello hace del abandono de la cuestión semántica una medida aconsejable. En adelante se va a seguir utilizando la referencia al pueblo en un sentido que intenta abarcar tanto la nación como el pueblo, entendidos como una comunidad política ${ }^{28}$. La pregunta que debe abordarse a continuación es qué es el pueblo como comunidad política.

El pueblo es un conjunto de individuos que vive bajo un mismo dominio estatal. Sin embargo, en la historia occidental el concepto de pueblo ha sido difícil de determinar. Puede sostenerse que el pueblo fue la población que habitaba un territorio donde se formó un Estado, por ejemplo, el caso Suizo; como también puede sostenerse que pueblo es un grupo con identidad cultural o espiritual bien definida que formó un Estado: el caso alemán. Sin embargo, más allá de cómo el pueblo haya constituido su relación con el Estado, puede decirse que el pueblo es el conjunto de individuos vinculados con un Estado: son el pueblo del Estado.

El pueblo tiene dos dimensiones. Es, por un lado, la agregación de todos y cada uno de los individuos de una sociedad, lo que constituye, en suma, nada más que un conjunto de individuos. Pero cuando ese conjunto de individuos -el pueblo en sentido agregativo- tiene una unidad política, ya no puede hablarse de pueblo sin más, sino que debe hablarse de pueblo como comunidad política.

La decisión del pueblo de conformar una unidad política puede ir acompañada del hecho de formar una unidad espiritual o una unidad cultural. Sin embargo, es perfectamente posible que la unidad política tenga autonomía respecto de otras dimensiones de unidad en la sociedad ${ }^{29}$. Es posible que la decisión de formar una unidad espiritual o cultural no vaya acompañada por la de formar una unidad política (por ejemplo, los Catalanes o los Andaluces). Esta cuestión es particularmente interesante para elaborar el principio de libre determinación de los pueblos, un principio fundamental de la justicia política. Lo que caracteriza al pueblo como unidad política es el vínculo que se sostiene en la decisión común de vivir juntos y tomar parte tanto en los

${ }^{27}$ Así lo hacen el artículo 3 de la Constitución francesa, el artículo 1 de la Constitución italiana, el artículo 3 de la Constitución portuguesa, El artículo 1 de la Constitución española y el artículo 20 de la Ley Fundamental alemana.

${ }^{28}$ En una situación diferente se encuentran los Estados federales o con algún régimen de autonomía política. En relación al caso español, véase VARELA SuAnZes, Joaquín, cit. (n. 26), pp. 72-74. Con todo, esto es una cuestión que debe ser objeto de un estudio detallado que no puede llevarse a cabo aquí. Puede consultarse, sobre la discusión doctrinal sobre ella, Vega, F., Notas sobre la titularidad y ejercicio de la soberania en la constitución politica de 198", ponencia presentada en las XXXVIII Jornadas de Derecho Público (Universidad Católica de Chile, Santiago, 2009).

${ }^{29}$ BÖCKENFÖRDE, E. W., cit. (n. 2), p. 165. 
éxitos y beneficios, como en las responsabilidades y fracasos de la comunidad. En definitiva, decidir participar en la libertad y en la responsabilidad de guiar su destino como comunidad ${ }^{30}$.

La comunidad política como unidad, permite dar cuenta de una voluntad general del pueblo, distinta a la voluntad de cada uno de los individuos que lo conforman y distinta también de la mera agregación de dichas voluntades. Sin embargo, la comunidad política no es algo distinto al pueblo, es el pueblo mismo en su unidad política. El pueblo no puede actuar como sujeto sino conforme a su unidad. Puede ilustrarse esto mediante una analogía: la orquesta es un conjunto de músicos. Los músicos agregados hacen un conjunto de músicos. Sólo la voluntad de los músicos de permanecer y actuar con unidad hace que pueda predicarse a su respecto que ellos conforman una orquesta.

Si se entiende qué es el pueblo, puede concluirse también qué no es el pueblo. El pueblo, en primer lugar, no son todas las personas que habitan el territorio del Estado. El concepto de pueblo es un concepto esencialmente excluyente, así, los extranjeros no son parte del pueblo ${ }^{31}$. El pueblo tampoco hace referencia a una clase social, no hace referencia a los más pobres o los desfavorecidos por el sistema económico ${ }^{32}$. El pueblo tampoco son grupos y asociaciones sociales, aunque se apele a ella como un conjunto considerable. Lo que caracteriza a dichas asociaciones es la persecución de intereses propios -ya sean económicos, culturales o políticos- o la identificación por determinadas características. En ese sentido su participación en la vida política se realizará mediante la defensa de intereses y concepciones comunes, pudiendo servir como mediadores entre los individuos y el Estado.

c) El ejercicio de la soberanía popular. La aclaración anterior parecerá verse reducida por la afirmación que se realizará ahora que, sin embargo, debe considerarse con cuidado. ¿Cómo ejerce el pueblo la soberanía? La actuación del pueblo nunca puede ser llevada a cabo por el pueblo en su totalidad. Siempre será un sector del pueblo o algunos individuos aislados los que llevarán a cabo los actos de soberanía popular como agentes del pueblo. Es posible concluir, por tanto, que el pueblo es "capaz de buscar y crear sus propias formas de manifestarse" y que dichas formas no están de manera necesaria establecidas institucionalmente ${ }^{33}$. En palabras de Sieyès:

${ }^{30}$ Böckenförde, E. W., cit. (n. 2), p. 67. Böckenforde, ibíd.., p. 165, lo define como "el conjunto de hombres que se delimita y se reúne políticamente, que es consciente de sí mismo como magnitud política y que entra en la historia actuando como tal”.

${ }^{31}$ Sobre las cuestiones que se plantean sobre la relación del concepto de pueblo con los extranjeros, véase, BöCKENFÖRDE, E. W., cit. (n. 2), pp. 68 ss.

${ }^{32}$ BÖCKENFÖRDE, E. W., cit. (n. 2), p. 166.

${ }^{33}$ Böckenförde, E. W., cit. (n. 2), p. 167, Schmitt, Carl, Teoría de la constitución (Madrid, Alianza, 1983), pp. 99-100. 
"No importa la forma en que la nación quiera; basta que quiera. Todas las formas son buenas" 34 .

La atribución de la actuación del pueblo siempre es determinada como una interpretación retrospectiva. Se interpreta la actuación de determinados agentes como actuación del pueblo. De las masas obreras y campesinas contra el Zar y del Tercer Estado contra Versalles son quizás los ejemplos menos conflictivos. La atribución de la actuación del pueblo a un golpe de Estado militar latinoamericano, se aleja de los ejemplos históricos paradigmáticos y dependerá tanto de la interpretación de lo que pasaba en el país antes del golpe, como de lo que pasó después. Sólo después de la vuelta a la normalidad, es posible juzgar si ese golpe de Estado fue un acto de soberanía popular o no lo fue y si, por el contrario, fue un acto de usurpación de la soberanía por parte de una facción o de un individuo o grupo de individuos que perseguía intereses particulares. Ello dependerá fundamentalmente si a aquellos les "es posible presentarse con éxito como representante del pueblo político y, con ello, obtener reconocimiento" 35 .

La doctrina de la soberanía popular no se preocupa de manera especial de la elaboración del concepto de soberanía. Sí se preocupa de trasmutar el titular de la soberanía, del rey al pueblo ${ }^{36}$. Se puede sostener que la afirmación principal del principio de la soberanía popular es que la soberanía le pertenece al pueblo. El pueblo en su unidad, como comunidad política, es el titular de la soberanía.

d) El concepto de soberanía y el poder constituyente. En la medida que la soberanía pertenece a la comunidad política, la comunidad política no está sometida más que a su propia decisión a la hora de gobernarse. El pueblo es quien tiene la decisión última y esa decisión dependerá, claro, de un juicio político del pueblo. Ese será un juicio que no está sometido al Derecho ni a la constitución. Es en ese especial sentido que el pueblo tiene la soberanía. El pueblo es libre de toda dominación a la hora de decidir, en última instancia, sobre toda la realidad estatal. El ejercicio de dicha libertad pertenece, en definitiva, a una comunidad política que decide fijar su propio destino.

De esta manera, la principal innovación de la soberanía popular en relación al concepto mismo de soberanía es la afirmación de que se le reconoce al pueblo, una facultad de disposición plena sobre la ordenación y la configuración de las cuestiones políticas y sociales dentro del Estado.

Dado que el destino de la comunidad política no puede perseguirse por

\footnotetext{
${ }^{34}$ SIEYÈs, Emmanuel-Joseph, cit. (n. 22), p. 159.

${ }^{35}$ BÖCKENFÖRDE, E. W., cit. (n. 2), p. 165.

${ }^{36}$ BÖCKENFÖRDE, E. W., cit. (n. 2), pp. 163-5.
} 
otros medios que no sean la formación de un Estado, la titularidad de la soberanía como poder de decisión del pueblo trae como consecuencia necesaria un poder de disposición respecto de la constitución estatal. Esa disposición requiere la manifestación de la soberanía como un poder de excepción, en el que el orden estatal sea suspendido. En la medida que el estado de excepción no puede prolongarse por siempre, el pueblo soberano tiene siempre la posibilidad de alterar o mantener el orden estatal previo.

Sin embargo, en la medida que la soberanía reside en alguien distinto a quien ordinariamente ejerce el poder del Estado, es necesario incorporar un nuevo atributo a la soberanía. No ya un atributo negativo, como es el poder de excepción, sino un atributo positivo, que no estaba presente en las concepciones de Hobbes y Bodin. Un poder de crear un nuevo orden estatal y de determinar la forma en que va a ser ejercido el poder del Estado. Es así como el principio de soberanía del pueblo implica necesariamente el poder constituyente del pueblo ${ }^{37}$.

\section{Recapitulación.}

Se ha intentado posicionar las ideas de Bodin, Hobbes, Schmitt y Sieyès en torno a la soberanía en un relato que pretende integrar dos aspectos: concepto y titularidad de la soberanía. Estos dos aspectos, pretenden abordan dos dimensiones en las que el discurso de la soberanía se desenvuelve: el de la filosofía política y el de la teoría constitucional.

En el nivel de lo teórico, el concepto de soberanía es un concepto confuso y está lejos de ser unívoco. Se intentó presentar dos versiones. En Hobbes, se introdujo para presentar una justificación monolítica del ejercicio del poder político por parte del Estado, en particular, atribuyendo al monarca dicho ejercicio, fundado en el consentimiento de los súbditos ante la promesa de orden, paz y seguridad. En Hobbes, la soberanía es la conclusión de un método de justificación del poder del Estado. La soberanía es, por tanto, idéntica al poder del monarca, que es idéntico al poder del Estado. A esa versión se denominó soberanía comandante. Distinto es el caso de Bodin. La soberanía se erige como una de las fuentes del poder estatal, que sin embargo coexiste con otras fuentes dentro del contexto de un orden con múltiples polos de poder. Si bien Bodin buscaba encontrar un argumento para afirmar el poder absoluto del rey, lo sometía a límites. En la lectura de Schmitt de cómo la soberanía funcionó permite una reinterpretación que hace coincidir la teoría de la soberanía en Bodin con la afirmación de que la soberanía es el poder de decidir sobre la excepción.

Sieyès, por otro lado, comprende nuevamente la soberanía, en cuanto

${ }^{37}$ BöCKENFÖRDE, E. W., cit. (n. 2), p. 50. 
conclusión de la tesis contractualista, como una justificación monolítica del poder del Estado. La diferencia fundamental con Hobbes, radica en que el titular de la soberanía es el pueblo y no el monarca. Ello tiene como consecuencia, un cambio necesario en el concepto de soberanía que es clave, y que acerca su propuesta a las ideas de Bodin y de Schmitt: la soberanía no se ejerce ordinariamente y no es idéntica al poder del Estado. Por el contrario, se ejerce extraordinariamente y lo que se hace es conceder al poder del Estado, que está en manos de los representantes de la nación, su base y justificación. Ello en la medida que su titular ya no es el órgano estatal supremo, sino que es el pueblo, anterior y superior al propio Estado.

Así, puede intentar determinarse qué es lo que distingue la concepción de soberanía como poder para gobernar arbitrariamente el Estado, una soberanía comandante, como en Hobbes, de la soberanía como poder de excepción y como base de la legitimación del orden estatal y potencial constitución de un nuevo ordenamiento, la soberanía constituyente, como en Sieyès y Schmitt. Mientras que para el primero el énfasis está puesto en el momento de la coerción, para el segundo está puesto en la creación; mientras para el primero el ejercicio se basa en el modelo de gobernar, para el segundo se presenta como una actividad legislativa; mientras el poder de uno se ejerce desde arriba, en el otro el poder se ejerce por el pueblo, por la nación o por la comunidad ${ }^{38}$.

Puede observarse, entonces, que la soberanía en el nivel de la filosofía política, más que identificarse por su concepto, se identifica por la determinación de su titular. La atribución de la soberanía al monarca o al pueblo, dependerá, en definitivas cuentas, de la concepción de la libertad del hombre en relación al Estado que se considera necesaria. Para unos, la libertad se ve subordinada a la seguridad y requiere sólo manifestarse en el acto de consentimiento original. Para otros, los demócratas, la libertad positiva del pueblo para autodeterminarse requiere mucho más. En definitiva, puede observarse que la titularidad de la soberanía es una tesis de justicia política.

En una dimensión diferente, en el nivel de la teoría constitucional, es donde el concepto de soberanía extiende su riqueza y utilidad. Para abordar esa dimensión más específicamente, se ha considerado el recurso, ideado por Sieyès, de que la titularidad de la soberanía implica también la titularidad del poder constituyente.

\section{EL PODER CONSTITUYENTE DEL PUEBLO}

Es impresionante que la teoría del poder constituyente haya sido formulada de una manera tan nítida y se haya mantenido por tanto tiempo, desde

${ }^{38}$ Kalyvas, Andreas, cit. (n. 10), pp. 97 ss. 
su formulación, con una identidad inalterable. Vale la pena, tomando esto en consideración, revisar las palabras de Sieyès: “[...] Se nota bien la notable necesidad de someter al gobierno a formas ciertas, tanto internas como externas, que garanticen su aptitud respecto al fin para el que fue establecido y su impotencia para apartarse de ellas./ Pero que se nos diga según quépuntos de vista, según qué interés se habría podido dar una Constitución a la nación misma. Ella existe ante todo y es el origen de todo. Su voluntad es siempre legal; es la ley misma. Antes de ella, por encima de ella, no hay más que el Derecho natural. Si nosotros queremos formarnos una idea justa de la serie de leyespositivas que no pueden emanar más que de su voluntad, vemos, en primer lugar, las leyes constitucionales [...]. Estas leyes son llamadas fundamentales, no en el sentido de que puedan llegar a ser independientes de la voluntad nacional, sino porque los cuerpos que existen y obran gracias a ellas no pueden tocarlas ni violarlas. En cada una de sus partes la Constitución no es obra delpoder constituido, sino del poder constituyente. Ninguna clase de poder delegado puede cambiar nada en las condiciones de la delegación. En este sentido, las leyes constitucionales son fundamentales" 39 .

La fórmula de Sieyès presenta la teoría del poder constituyente como una argumentación que se preocupa de tres afirmaciones: $i$ ) el poder constituyente es un atributo de la soberanía; ii) el poder constituyente no esta regulado por el Derecho, luego, se distingue de los poderes constituidos; y iii) el poder constituyente es el fundamento de la supremacía constitucional.

\section{La teoria del poder constituyente.}

La teoría del poder constituyente, cuyo nacimiento puede identificarse, como se vio, conjuntamente con la soberanía popular, pretende explicar cómo la constitución puede ser puesta y configurada por determinadas fuerzas políticas de las cuales toma su validez. Por otro lado, pretende explicar también cómo esa fuerza política puede invalidarla. La teoría del poder constituyente, por tanto, pretende explicar tanto el origen como la validez de la constitución ${ }^{40}$.

La teoría del poder constituyente puede ser comprendida como una fórmula para afirmar la legitimidad de la constitución y del Estado, sin recurrir a una justificación jurídica, que no es posible sostener cuando las normas que se tratan de justificar son las que están en la máxima jerarquía del orden estatal. Así, como sostiene Böckenförde, el poder constituyente es un concepto límite del Derecho constitucional, dado que es aquello que sirve

\footnotetext{
${ }^{39}$ SIEYÈs, Emmanuel-Joseph, cit. (n. 22), p. 157.

${ }^{40}$ BöCKENFÖRDE, E. W., cit. (n. 2), p. 159.
} 
de bisagra entre el Derecho y aquello que está más allá del Derecho, que es el único lugar donde la constitución puede encontrar su validez ${ }^{41}$.

Puede definirse poder constituyente del pueblo como "la fuerza y la autoridad que corresponden al pueblo (en el sentido de una competencia preconstitucional) para establecer una Constitución con pretensión normativa de vigencia, para mantenerla y cancelarla" ${ }^{\prime 2}$.

El poder constituyente es la capacidad del pueblo de darse una constitución. Antes del ejercicio del poder constituyente el pueblo es un sujeto sin forma y que no se sujeta a formas a la hora de actuar. Con la implantación de la constitución, el pueblo se da forma estatal y así queda formalizada la actuación de la comunidad política. El orden jurídico estatal que la constitución implanta constituye una renuncia (temporal) del pueblo a actuar de manera diferente a la establecida en la constitución. Una vez establecida la constitución, son las potestades allí establecidas y reguladas las que ejercen el poder político con base en la constitución. Al ejercicio de dichos poderes es que se llama potestades o poderes constituidos. Como Schmitt afirma: "En el poder constituyente descansan todas las facultades y competencias constituidas y acomodadas en la Constitución. Pero él mismo no puede constituirse nunca con arreglo a la Constitución. El pueblo, la Nación, sigue siendo el basamento de todo el acontecer político, la fuente de toda la fuerza, que se manifiesta en formas siempre nuevas [...] no subordinando nunca, sin embargo, su existencia política a una formulación definitiva" ${ }^{\not 3}$.

\section{Caracteristicas del poder constituyente.}

De la descripción anterior pueden recogerse las siguientes características del poder constituyente del pueblo.

a) Es un poder fundacional. La teoría del poder constituyente significa un nuevo comienzo y por tanto ocurre fuera del horizonte constitucional, porque pretende justamente redefinir radicalmente sus contornos y contenido: "Si el poder constituyente estuviera determinado por el orden legal anterior, o si derivara su legalidad de una constitución preexistente, no sería un poder constituyente, sino un poder constituido. Esto explica

${ }^{41}$ BÖCKENFÖRDE, E. W., cit. (n. 2), pp. 160-2. Los vacíos que presentan las teorías acerca del sistema jurídico cuando se enfrentan a la necesidad de justificar la validez jurídica de la constitución, las hace recurrir a fórmulas vacías del tipo de la norma fundamental hipotética (Kelsen, Hans, Teoría general del Derecho y del Estado (México, Universidad nacional autónoma de México, 1969), pp. 135-9). La teoría del poder constituyente viene a llenar aquel vacío.

${ }^{42}$ Böckenförde, E. W., cit. (n. 2), p. 50. Puede confrontarse con Schmitt, Carl, cit. (n. 33), p. 93.

${ }^{43}$ Schmitt, Carl, cit. (n. 33), p. 97. 
una imposibilidad lógica que borra el propio significado y la existencia del término poder constituyente" ${ }^{44}$.

Ello implica que el poder constituyente no puede estar sometido por reglas y procedimientos preestablecidos. Las razones más concretas que sustentan dicha afirmación son: $i$ ) que si la excepción, como expresión de la soberanía, es la condición del ejercicio del poder constituyente, es lógico que el orden estatal no ejerza vinculación alguna, dado que está suspendido; y ii) que justamente mediante el establecimiento de una nueva constitución tal orden estatal es dejado atrás. Ello dice estrecha relación con la asociación que puede hacerse entre la actuación del poder constituyente y el fracaso o colapso del orden estatal anterior ${ }^{45}$.

b) Es el ejercicio de la actividad humana. Un elemento fundamental de la teoría del poder constituyente es que comprende a la constitución como una creación humana. Representa una instancia de autodeterminación de la propia comunidad, que deja atrás formas impuestas por voluntades ajenas o por la naturaleza: "Una constitución representa un intento tentativo y precario de organizar libre y conscientemente la forma política de una existencia colectiva. No es dada por la naturaleza, ni una necesidad ineludible, ni un lamentable simulacro de una ley natural eterna y ficticia que proporciona el prototipo transhistórico ideal para todas las constituciones”46.

En la medida que ningún orden estatal puede restarse de la tarea de justificarse, la afirmación que imputa dicha justificación al poder constituyente hace depender el orden estatal de la voluntad del pueblo, que no se presenta como un mero hecho sino como "una magnitud que precede y aparece como un poder o autoridad especial" 47

La particularidad de la teoría del poder constituyente es que no deja la cuestión del fundamento del orden estatal en manos de la presuposición de una norma hipotética, ni obtiene determinado fundamento normativo ideal de orden iusnaturalista, que pueda actuar como norma fundamental, sino que entrega dicho fundamento a una voluntad política sustentada por el pueblo: "Las ideas de justicia [...] sólo cobran fuerza configuradora y legitimadora para la vida en común de los hombres cuando son mantenidas por hombres o grupos de hombres como una convicción viva, y se integran en una fuerza o una magnitud política que las sostiene" ${ }^{48}$.

c) Es un poder que no obedece a formas. Al igual que la soberanía, el poder constituyente no obedece a formas preestablecidas. Especialmente

\footnotetext{
${ }^{44}$ Kalyvas, Andreas, cit. (n. 10), pp. 99-100

${ }^{45}$ Kalyvas, Andreas, cit. (n. 10), pp. 100-101.

${ }^{46}$ Kalyvas, Andreas, cit. (n. 10), p. 101.

${ }^{47}$ BÖCKENFÖRdE, E. W., cit. (n. 2), p. 162.

${ }^{48}$ BöCKENFÖRDE, E. W., cit. (n. 2), pp. 162-164.
} 
porque dichas formas legales están establecidas en el orden estatal que el poder constituyente reemplazará. Sin embargo, la manera radical en que el ejercicio del poder constituyente es espontáneo y extrainstitucional, supera con creces el baremo de la ilegalidad, en la medida que su finalidad es desafiar directamente la estructura de poder sobre la cual se sostiene el orden estatal existente ${ }^{49}$. Para ese objetivo, al igual que la soberanía, "es él mismo quien es capaz de buscar y crear sus propias formas de manifestarse" ${ }^{\text {" }}$. En ese sentido se distingue categóricamente de los poderes constituidos.

\section{El poder constituyente y los poderes constituidos.}

Los poderes constituidos tienen como característica la formalidad. Ellos están sometidos y disciplinados por las normas constitucionales que los constituyen. La constitución se concibe como parámetro de validez del ejercicio de esos poderes. Entre esas potestades constituidas por el poder constituyente, se encuentra, junto con la potestad legislativa, ejecutiva y judicial, la potestad de modificar la constitución. También la potestad constituida de reformar la misma constitución es, entonces, un poder sometido a las formas jurídicas de la propia constitución, es una potestad y no un poder. El único poder constituyente es el que se ejerce directamente por el pueblo, sin la mediación de la forma jurídica estatal.

Así las cosas, lo que interesa para determinar los contornos del poder constituyente, es distinguir entre el poder de crear una constitución desde la nada y el poder de modificar esa constitución recurriendo a los procedimientos establecidos en la misma constitución ${ }^{51}$. La base sobre la cual debe construirse esta distinción es que el poder constituyente, esto es, el que constituye el orden jurídico estatal, no puede estar determinado por ese mismo orden estatal, sino que debe preceder a las potestades estatales que son constituidas, organizadas y limitadas por él: el poder constituyente no es una manifestación del poder estatal, sino que es anterior a él ${ }^{12}$.

\section{El poder constituyente y la supremacía constitucional.}

El poder constituyente no puede ser regulado por la constitución misma y en ese sentido la constitución no establece una forma de actuación para un poder que se caracteriza, justamente, por no estar sometido a formas.

Con la distinción entre poder constituyente y poder constituido, surge la duda en relación a qué ocurre con el poder constituyente una vez que éste se ha dado una constitución. La respuesta que se dé a esta pregunta

\footnotetext{
${ }^{49}$ Kalyvas, Andreas, cit. (n. 10), pp. 102-103.

${ }^{50}$ BöCKENFÖRDE, E. W., cit. (n. 2), p. 167.

${ }^{51}$ Schmitt, Carl, cit. (n. 33), p. 114.

${ }^{52}$ BöCKENFÖRDE, E. W., cit. (n. 2), p. 163.
} 
dependerá de si se entiende que la fuerza y validez de la constitución se basa en un acto de establecimiento constitucional o si dicha validez se basa en una decisión permanente del pueblo como titular de la soberanía y el poder constituyente $\mathrm{e}^{53}$.

Si se concibe que el poder constituyente se agota en el acto de establecimiento de la constitución, la soberanía se extingue en la normalidad constitucional y puede concluirse que en el Estado constitucional no existe un soberano o que el soberano deja de ser el pueblo para constituirse en el Estado mismo. En la sección siguiente se abordará esa hipótesis.

$\mathrm{Si}$ se concibe, en cambio, que el poder constituyente sigue presente de una forma latente tras el establecimiento de la constitución, de manera que volver a manifestarse es una cuestión posible, se está confiriendo una validez permanente a la constitución, mediante la decisión de su mantenimiento. En este caso, el soberano es y sigue siendo el pueblo, inclusive en el Estado constitucional. Si se considera, como Böckenförde, que "el poder constituyente del pueblo tiene por sí mismo la fuerza de legitimar la Constitución jurídica -y se puede apelar a él para ello-, entonces hay que reconocer que tiene también la fuerza de cancelar esta legitimación [...]"\$4.

El ejercicio del poder constituyente es algo permanente, no es algo que se ejerza en un acto que tiene una entidad temporal determinada. "La fuerza normativa de la Constitución depende de ello" en la medida que lo que determina el fundamento y la cohesión del orden político queda a disposición plena del pueblo. Cuando el pueblo es titular del poder constituyente, la constitución, el Estado y el orden jurídico vigente descansan sobre su decisión de mantener la normalidad. En este sentido, si bien debe concluirse que el Estado constitucional no está libre de un nuevo ejercicio del poder constituyente, puede advertirse que las disposiciones de la constitución pueden intentar dar un cauce que no necesariamente desemboque en un quiebre institucional. Esa es la idea sobre la que se construye el sistema de modificación de la constitución por la potestad constituyente derivada y la adopción de un sistema de gobierno democrático. Las expresiones directas del poder constituyente quedan, de esta manera, reducidas a las situaciones extraordinarias: a la excepción ${ }^{55}$.

\section{La soberania popular, el poder constituyente y la democracia}

La relación entre soberanía y democracia es quizás una de las más confusas entre principios constitucionales. Es curioso que la mejor manera de abordar

\footnotetext{
${ }^{53}$ BöCKENFÖRDE, E. W., cit. (n. 2), p. 168.

${ }^{54}$ BÖCKENFÖRDE, E. W., cit. (n. 2), p. 169.

${ }^{55}$ Böckenförde, E. W., cit. (n. 2), pp. 169-76, Schmitt, Carl, cit. (n. 33), p.
} 101. 
esa relación se encuentre en la distinción entre formas de Estado y formas de gobierno, también obra de Bodin.

Para Bodin, en congruencia con la utilización de su tesis sobre la soberanía, que la titularidad de la soberanía correspondiera al rey no implicaba necesariamente que su ejercicio también correspondiera a éste. Las formas de Estado, correspondientes a los regímenes de atribución de la soberanía, podían ser monárquico, aristocrático y democrático. Las formas de gobierno, cuyo criterio definitorio era el órgano que ejercía el gobierno, también podían ser monárquicas, aristocráticas o democráticas. Era concebible, por ejemplo, una forma de Estado democrática con un gobierno monárquico, si es que la soberanía residía en el pueblo pero el gobierno era encomendado a un rey ${ }^{56}$.

En el caso de la soberanía popular, si ella atribuye el poder fundamental respecto a la configuración del orden político y social al pueblo, esto es, el pueblo es el origen del poder del Estado y es su portador último, la democracia como forma de gobierno implementa la idea de la soberanía popular de una manera más radical aún ${ }^{57}$. Si la soberanía es el fundamento del ejercicio del poder estatal por parte del Estado, la democracia como la forma de gobierno de un Estado, exige que sea el pueblo el que ejercite, de manera más o menos relevante, dicho poder.

Ello tiene dos implicaciones dignas de señalar. En primer lugar, la democracia es la forma en la cual la soberanía popular puede desencadenarse en el Estado constitucional, en la medida que el mismo titular de la soberanía será quien ejerza el poder del Estado. Pero, en segundo lugar, y de manera casi contradictoria, la democracia es la decisión constitucional que permite limitar la expresión excepcional del poder constituyente del pueblo. La democracia comprende la regulación de la expresión de las manifestaciones políticas de la comunidad, sirviendo como una válvula de escape. Dicho de otra manera, en la medida que la expresión de voluntad del pueblo puede canalizarse a través de los órganos representativos, el estándar para la actuación del poder constituyente se elevará de forma que sólo podrá manifestarse en una situación excepcional. Puede usarse la siguiente metáfora para explicar esa función de la democracia: la democracia funciona, respecto al poder constituyente, como la compuerta de una presa, que deja pasar el agua sólo en la medida racionalmente necesaria para su utilización, estando al mismo tiempo, sirviendo de barrera al cauce natural del río.

\footnotetext{
${ }^{56}$ Bоввіо, Norberto, cit. (n. 5), pp. 86 ss.

${ }^{57}$ BÖCKENFÖRdE, E. W., cit. (n. 2), p. 52.
} 


\section{LAS CRÍTICAS A LA TEORÍA DE LA SOBERANÍA POPULAR Y DEL PODER CONSTITUYENTE DEL PUEBLO}

Las críticas que la teoría de la soberanía del pueblo y del poder constituyente han recibido, dicen relación, en su mayoría, con la incomprensión liberal de que el Derecho no puede someter totalmente a la política; la política no puede ser neutralizada por el Derecho y sus instituciones. Por otro lado, las críticas vienen de la incomprensión metodológica de algunos autores, de la necesidad de encontrar un fundamento al Derecho que vaya más allá del propio derecho. En la medida que el Derecho es “decidido" o "puesto", existe un momento en que dicha acción no está sujeta a su vez a un procedimiento regulado por el propio Derecho ${ }^{58}$.

\section{Criticas conceptuales dirigidas a la teoría de la soberanía popular-}

Es común la utilización del término soberanía en un sentido totalmente distinto del que se viene utilizando. Es común, por ejemplo, la utilización de la soberanía como soberanía del Estado. Ese uso de la soberanía puede tener dos explicaciones que, como veremos, no están del todo justificadas. Ellas son: (1) la soberanía no existe en el Estado constitucional y (2) la soberanía es, en realidad, un atributo del Estado. Esta última afirmación es susceptible de dos lecturas diversas, que recaen sobre las ideas de soberanía del Estado hacia el interior y soberanía del Estado frente a los demás Estados.

a) En el Estado constitucional no hay soberano. La primera posición descrita es sostenida por Martin Kriele. Si bien Kriele adhiere a las premisas de la soberanía popular como fundamento de la constitución y el Estado, considera que la subsistencia de la soberanía del pueblo es incompatible con el Estado constitucional. El Estado constitucional y la afirmación de los principios constitucionales que implican separación de poderes, derechos fundamentales, legalidad y, en especial, supremacía constitucional, son incompatibles con la mantención del pueblo como soberano, es más, “constituyen su negación" 59 . La soberanía no puede, entonces, reconocerse en el orden constitucional. En él, sólo son reconocibles los poderes constituidos. Luego, la soberanía del pueblo no significa que el pueblo ejerza el poder, sino que el poder del Estado proviene del pueblo. Incluso cuando la constitución le atribuye competencias al pueblo, esa referencia toma al pueblo como un poder constituido sometido a la constitución. En ese sentido es que Kriele entiende que en el Estado constitucional no hay soberano: "[l]a soberanía del

${ }^{58}$ De Oтto, Ignacio, Derecho constitucional. Sistema de fuentes (Barcelona, Ariel, 1988), pp. 20-2.

${ }^{59}$ Kriele, Martin, cit. (n. 3), p. 316. 
pueblo sólo aparece al comienzo o al final del Estado constitucional, cuando éste es creado y cuando éste es abolido [... e]l soberano democrático renuncia a su soberanía al hacer uso del poder constituyente"60.

Ello, se contrapone a lo que se ha afirmado aquí respecto de la presencia necesaria e inevitable de la soberanía y del poder constituyente. El pueblo que se ha dado la constitución tiene, inalienablemente, como se ha dicho más arriba, el poder para abolirla, más allá que el Estado constitucional sea la expresión de la limitación de dicho poder. El soberano y su poder constituyente sólo pueden estar en suspenso, pero nunca ser eliminados ${ }^{61}$.

Adicionalmente, se puede señalar que al eliminarse el poder constituyente del pueblo del horizonte constitucional, surgen las ambiciones soberanas que podrían tener las diferentes ramas del Estado, en especial la legislativa, lo que reduciría la soberanía a la representación y en definitiva al poder de los órganos estatales ${ }^{62}$.

b) La transformación de la soberanía del pueblo en la soberanía del Estado. En la primera parte de este trabajo se concluyó que Hobbes comprendía la soberanía como un atributo del Estado. Ello era así en la medida que existía una identidad personal entre el monarca soberano y el Estado. Ello resulta incompatible con la idea de la soberanía popular. Sin embargo, la afirmación de que no es el pueblo sino el Estado quien ejerce la soberanía es una idea ampliamente difundida.

La idea de que la soberanía reside en el pueblo pero es ejercida por el Estado puede resultar problemática si no se toma con cuidado. Se señaló que la soberanía no reside, que su titular no es, el Estado. Se afirmó que si bien la soberanía reside en el pueblo, el pueblo como sujeto unitario no tiene capacidad de acción, por lo que la acción del pueblo siempre será una imputación a la acción de cierto individuo o facción. Así las cosas, es perfectamente coherente la idea de que la soberanía reside en el pueblo pero es ejercida por el Estado.

Sin embargo, esta afirmación no se toma en serio el concepto de soberanía y disuelve la soberanía en el imperio del Derecho y el monopolio estatal de la fuerza. Si definimos al Estado por la titularidad del monopolio de la violencia legítima, la idea de definir la soberanía como dicha titularidad es, en sí misma, un sinsentido. La negación de la titularidad de la soberanía en estos términos, esto es, la afirmación de que el Estado no es soberano, es

\footnotetext{
${ }^{60}$ Kriele, Martin, cit. (n. 3), p. 318. Véase, en el mismo sentido, De Otto, Ignacio, cit. (n. 58), pp. 137-140.

${ }^{61}$ Schmitt, Carl, cit. (n. 33), p. 108.

${ }^{62}$ Kalyvas, Andreas, cit. (n. 10), p. 102.
} 
equivalente a decir que el Estado no es Estado. Estado soberano, por tanto, es equivalente a decir que el Estado es Estado ${ }^{63}$.

Con todo, si tomamos en cuenta la soberanía del pueblo, como poder de decidir sobre la excepción o la normalidad, es más coherente pensar que el fundamento del ejercicio del poder por parte del Estado tiene su base en la decisión del pueblo de mantener la normalidad constitucional que él puede suspender, para modificar o cancelar. Esa decisión justifica el poder coercitivo monopólico del Estado, pero sobre todo, justifica el orden constitucional como una decisión de carácter soberano. Es en ese sentido, indirecto por cierto, que es correcto hablar de que el Estado y sus órganos ejercen la soberanía: ejercen el poder que la constitución como decisión del soberano les atribuye ${ }^{64}$.

Puede entenderse por qué algunos sostienen que la noción de soberanía para los periodos normales, se reduce, al concepto jurídico de ejercicio legítimo del poder por parte de los órganos del Estado. No obstante la plausibilidad de dicha afirmación, no puede aceptarse que se utilice el concepto de soberanía para señalar la actuación de los órganos estatales. Lo que se deposita en los órganos y autoridades que la constitución establece, no es en ningún caso la soberanía, la constitución no delega la soberanía. Lo que delega y lo que deposita en los órganos constitucionales mediante el ejercicio del poder constituyente es sólo el poder de dirigir o gobernar, el que puede radicarse ya sea en un rey, como en la constitución francesa de 1789 , como en órganos representativos como una asamblea o un presidente del gobierno. Dicha delegación puede ser hecha de forma temporal o permanente. No obstante la enajenación del ejercicio normal del poder, dicha delegación no cancela el principio de la soberanía popular "mientras la decisión de transferir el poder de gobernar se mantenga jurídicamente como algo revocable"65. Con esto, puede entenderse que el ejercicio del poder de gobierno que corresponde a los órganos que la constitución establece no puede ser tomado en serio como el ejercicio de la soberanía popular ${ }^{66}$.

${ }^{63}$ Confrontar CARRÉ de MAlberg, Raymond, cit. (n. 1), pp. 83-91.

${ }^{64} \mathrm{La}$ doctrina del Derecho público alemán es ajena a la tradición de la soberanía popular y durante todo el siglo XIX afirmó la soberanía del Estado. Desde Weimar la imputación de la soberanía al pueblo en la propia constitución no ha hecho más que desbaratar tal idea. Sobre la evolución del concepto de soberanía en el Derecho público alemán puede consultarse WydUCKEL, Dieter, cit. (n. 3). La canónica presentación de la teoría de la soberanía del Estado, en Jellinek, Georg, Teoría general del Estado (México, Fondo de Cultura Económica, 2000), pp. 432-444.

${ }^{65}$ Böckenförde, E. W., cit. (n. 2), p. 50.

${ }^{66}$ Algunos argumentos de los defensores de la teoría de la soberanía del Estado, que sin embargo intentan hacerse cargo del problema sistemático de la consagración constitucional de la soberanía popular pueden verse en Varela SuAnzes, Joaquín, cit. (n. 26). 
c) La soberanía del Estado como soberanía externa. El concepto de soberanía estatal es estéril para explicar el fenómeno del poder constituyente, que es el principal atributo de la soberanía popular. Sin embargo, el concepto de soberanía del Estado ha permitido afirmar la noción de Estado como sujeto de Derecho internacional. Se habla, en ese entendido, de la dimensión externa de la soberanía.

La soberanía externa consiste en un principio de las relaciones entre los Estados; principio que afirma la independencia del Estado respecto de otros Estados y el deber de no ingerencia de dichas potencias extranjeras en las cuestiones estatales internas, ambas ideas basadas en la igualdad existente entre los Estados.

Es particularmente clara la afirmación de Kriele en referencia a la relación que existe entre el concepto de soberanía del Estado en el Derecho internacional y el concepto de soberanía popular: "Si definimos la "soberanía externa" como independencia e igualdad de los Estados, entonces el concepto se ha alejado tanto de su raíz histórica, como de su contenido propio y se ha hecho independiente. Más aún, se ha rendido frente a su propia imposibilidad, al absorber en sí el concepto contrario. Pues independencia e igualdad de los Estados no significan otra cosa que el reconocimiento de la obligatoriedad de las normas básicas del Derecho internacional. La soberanía del Derecho internacional es, por tanto, una contradicción en sí, pues significa tanto como la no-soberanía" ${ }^{\prime 6}$.

Sin embargo, no es posible negar la existencia de un vínculo entre el concepto de soberanía popular y el principio de la soberanía externa del Estado, que es una expresión de la libertad o autodeterminación de los pueblos y, de esa forma, además de un principio de Derecho internacional es un principio de justicia política ${ }^{68}$. En la medida que la autodeterminación del pueblo se puede entender como una libertad del pueblo respecto del Estado, el Derecho establecido y respecto de los individuos que componen tal pueblo, se trata de la afirmación de la soberanía popular como una soberanía interna. Cuando la afirmación se dirige a afirmar la libertad del pueblo respecto de los extranjeros, de otro pueblo y otro Estado que no es reconocido como propio, también puede hablarse de soberanía popular, pero esta vez desde una perspectiva externa.

2. Críticas dirigidas a la teoria del poder constituyente del pueblo.

a) El carácter ilimitado y arbitrario del poder constituyente.

${ }^{67}$ Kriele, Martin, cit. (n. 3), p. 83.

${ }^{68}$ Véase Rawls, John, El Derecho de gentes (Barcelona, Paidós Iberica, 2001), pp. 74-76,133-139. 
Ignacio de Otto presenta una crítica contra la idea, hasta aquí defendida, de que el poder constituyente del pueblo puede servir de fundamento a la validez de la constitución. De Otto considera que el fundamento de validez de la constitución podría recaer en un ejercicio del poder constituyente del pueblo únicamente allí donde éste se adapte a las formas democráticas del tipo asamblea constituyente o referéndum. En otro caso, no será el pueblo, sino alguien más quien estará ejerciendo ese poder constituyente. Así, en la medida que el poder constituyente debe someterse a formas para la consecución de la legitimidad que persigue, no puede ser considerado como un poder pre-jurídico, y en la medida que el poder constituyente es ejercido por el pueblo, es siempre un poder constituido ${ }^{69}$.

A esta crítica puede responderse con algo ya sostenido más arriba. La actuación del pueblo en ejercicio del poder constituyente es desformalizada, porque el pueblo mismo, como unidad política, no tiene forma. La adecuación a procedimientos democráticos es una estrategia para intentar dar legitimidad popular al ejercicio del poder constituyente, pero no es lo que hace que el ejercicio de dicho poder sea posible. La manifestación del poder constituyente es perfectamente posible a través de procedimientos no democráticos, si se enmarca dentro de un proceso político que lleve a que la comunidad política, con posterioridad al reestablecimiento de la normalidad constitucional puede entender que dicha actuación puede serle imputada como una actuación propia.

A esa respuesta, sin embargo, subyace un flanco más débil de la teoría del poder constituyente y de la soberanía considerada como poder de excepción, y se refiere al carácter arbitrario del poder constituyente del pueblo, esto es, a la falta de sujeción a estándares predefinidos para la evaluación de la creación del poder constituyente, el problema comprende la falta de criterios de reconocimiento para determinar cuándo es realmente el soberano el que ha hablado.

La respuesta a esta crítica pasa por entender, en primer lugar, que el poder constituyente es un concepto puramente teleológico y que se realiza a si mismo mediante la creación de un nuevo orden estatal, esto es, una nueva constitución. Pero "esto no quiere decir que carezca de leyes o normas por sí mismo, sino más bien que es la única fuente del poder legal, la única voz de razón, que puede producir normas jurídicas en una situación de desorden [...] no está vacío normativamente porque es permeado por consideraciones legales y impulsado y sobredeterminado por un objetivo legal" ${ }^{70}$.

En la medida que el objetivo del poder constituyente es constituir un

${ }^{69}$ De Otтo, Ignacio, cit. (n. 58), pp. 53-54.

${ }^{70}$ Kalyvas, Andreas, cit. (n. 10), p. 109. 
nuevo orden estatal, está imbricado en su concepto mismo el potencial constitutivo y, por tanto, ordenador y legislador.

En segundo lugar, para descartar la crítica de la arbitrariedad, se debe señalar que ciertos estándares pueden encontrarse dentro del concepto mismo del poder constituyente. La creación de una constitución es un acto de limitación del poder. En esa medida no puede achacársele arbitrariedad al acto de quién, partiendo desde una posición donde tiene el poder de actuar arbitrariamente, se autolimita mediante el acto constituyente. $\mathrm{Su}$ poder discrecional pero teleológico constituye el estándar de legitimación del poder constituyente ${ }^{71}$.

De esta característica conceptual del poder constituyente algunos autores, como Habermas, han querido concluir algunas bases de orientación mínimas para poder evaluar la actuación del poder constituyente. Así, entre los principios implícitos, pueden encontrarse la igualdad, la reciprocidad y el diálogo entre los intervinientes en el acto constituyente, llegando incluso a afirmar que en dichos principios se contiene todo el contenido de la democracia constitucional ${ }^{72}$.

b) La estabilidad de la constitución frente al poder constituyente. De Otto cuestiona, por otro lado, que el poder constituyente del pueblo pueda ser limitado por la constitución y seguir siendo un poder constituyente. Si el pueblo es el titular del poder constituyente, éste puede en cualquier minuto de la vigencia de la constitución, modificarla sin someterse al procedimiento jurídico establecido para ello. Pero eso sería, al mismo tiempo, violar la constitución. Luego, surge la pregunta de si puede ser el poder constituyente del pueblo fundamento de la validez de la constitución sin que con ello se justifique que el pueblo puede violar la constitución. Esta paradoja hace concluir a De Otto que el poder constituyente del pueblo no es compatible con la idea de la supremacía constitucional: "si el pueblo tiene el poder constituyente, la Constitución no lo limita, y si la Constitución lo limita, el pueblo no tiene el poder constituyente"73.

Este segundo argumento de De Otto, nuevamente, se basa en su equivocada comprensión de lo que el concepto de pueblo representa en la teoría del poder constituyente. El poder constituyente del pueblo es el poder de la comunidad política informe; por supuesto que no es el poder del pueblo como poder constituido por la constitución (electorado o ciudadanía). La constitución puede entenderse como un límite, especialmente a través de

${ }^{71}$ Kalyvas, Andreas, cit. (n. 10), p. 111.

${ }^{72}$ Kalyvas, Andreas, cit. (n. 10), pp. 112-4. Habermas, Jürgen, Facticidad y validez (Madrid, Trotta, 1998), pp. 147 ss.

${ }^{73}$ De Otto, Ignacio, cit. (n. 58), p. 55. En el mismo sentido, Varela Suanzes, Joaquín, cit. (n. 26), pp. $87 \mathrm{ss}$ 
la supremacía constitucional, frente al pueblo dentro del Estado constitucional. Pero una vez que el Derecho y la constitución han sido suspendidas por una manifestación de la soberanía, el pueblo como comunidad política es quien tiene el poder constituyente que, por supuesto, no es limitado por la constitución ${ }^{74}$. Sin embargo, no es posible separar diametralmente las dos dimensiones del pueblo: el pueblo constitucional y el pueblo soberano. "Los dos son en último extremo el mismo pueblo"75.

Ello, sin embargo, no supone, como parece sugerirse por la crítica, que el poder constituyente necesariamente transforme a la constitución en una ilusión. "[¿C]ómo es posible que la Constitución jurídica, sin desvincularse de su legitimación por el poder constituyente pueda, no obstante, proteger el fundamento y la persistencia de su validez frente a las oscilaciones de un poder no vinculado[?]”. Para ellos pueden ofrecerse tres razones.

En primer lugar, existen arreglos institucionales que permiten canalizar el poder constituyente a través de la participación del pueblo en las instituciones constituidas ordinarias. La expresión más importante de dichos arreglos es la instauración de un gobierno democrático.

En segundo lugar, es usual la consagración de un sistema de modificación constitucional que no involucre la manifestación violenta del pueblo frente a las instituciones constitucionales. En la medida que la propia constitución consagra su procedimiento de reforma, en el que la intervención del pueblo y sus representante es considerada, los canales ilegales de manifestación del poder constituyente se harán más gravosos y "las acciones que afectan de modo sustancial a la Constitución se ven de esta forma reducidas a situaciones extraordinarias, y necesitan de una especial energía para hacerse valer frente a la vida constitucional organizada" ${ }^{\text {" }}$.

Finalmente, debe señalarse que la constitución, que ha sido fruto de la acción del poder constituyente, expresa, como se ha señalado, una voluntad constitutiva. La modificación de la constitución y la expresión insurreccional del poder constituyente sólo se expresarán allí donde la identificación entre constitución y pueblo esté demasiado erosionada. En referencia a esta última instancia, es obligatorio asumir que el objetivo de la estabilidad de la constitución no es algo que pueda ser conseguido de forma absoluta ${ }^{77}$.

\section{La soberania y el poder constituyente: entre la politica y el Derecho.}

Fernando Atria ha aplicado el concepto de soberanía y de poder constituyente para analizar los hechos ocurridos en Chile entre 1973 y 1990. La

\footnotetext{
${ }^{74}$ En este sentido, véase VARela Suanzes, Joaquín, cit. (n. 26), p. 91

${ }^{75}$ BÖCKENFÖRDE, E. W., cit. (n. 2), p. 173.

${ }^{76}$ BÖCKENFÖRDE, E. W., cit. (n. 2), p. 170.

${ }^{77}$ BöCKENFÖRDE, E. W., cit. (n. 2), p. 169.
} 
conclusión a la que arriba es que la interpretación de dichos hechos es mejor, en la medida que puede recurrirse al concepto de soberanía para catalogar el ejercicio del poder durante la dictadura. Para aquellos que creen que el 10 de septiembre de 1973 Chile vivía un profundo mal e imputa hoy a las autoridades del ejército que bombardearon La Moneda la materialización de haber actuado por el bien de Chile, fue el soberano el que tomó la decisión de diagnosticar el estado de excepción y los generales sólo fueron el canal a través de la que actuó. Para aquellos que creen que el golpe de Estado fue un atentado contra la legítima autoridad, los generales -con el apoyo de la derecha y la democracia cristiana- instauraron una dictadura soberana en la que la soberanía fue ejercida por una facción y no por el pueblo.

Pero por sobre todo, y esto no puede ser objeto de tratamiento aquí, tal concepto de soberanía es capaz de iluminar el conflicto político de la comunidad chilena, en torno a cuál es la identidad de la comunidad política y quiénes la componen. Esto es, iluminar sobre la cuestión de si los hechos acontecidos entre 1970 y 1990 permiten hablar de una comunidad política fracturada o permiten algo como lo que se ha tendido a llamar la reconciliación. La actual comprensión acerca de la cuestión del ejercicio de la soberanía puede echar luz sobre el asunto de la identidad de la comunidad política nacional.

En este ejercicio Atria considera a la soberanía y a la constitución desde una dimensión eminentemente política. Y a ese respecto, debe volverse sobre el objetivo de aclarar la perspectiva de análisis en que se desarrolla cada uno de los discursos acerca de la soberanía. Atria sugiere que la soberanía y el poder constituyente requieren discutirse fuera del análisis jurídico, porque parece tratarse de un fenómeno que escapa al código jurídico; se trata, de un problema que se mueve en una dimensión inaprensible para el Derecho, que es justamente la del juicio histórico sobre la legitimidad política del Estado. El código político de lo posible e imposible y el código de la filosofía política sobre lo legítimo y lo ilegítimo no pueden aprenderse por el código legal e ilegal propio del Derecho ${ }^{78}$.

La pregunta subsecuente es si puede el fenómeno de la soberanía y del poder constituyente, tematizarse por el Derecho. ¿Puede ser el Derecho reflexivo ante la soberanía y el poder constituyente? Atria parece sugerir que no. En la medida que la soberanía y el poder constituyente son fenómenos políticos, que se caracterizan fundamentalmente por la ausencia de forma jurídica, al intentar juridificarlos, simplemente se atrofia su correcto significado y se los saca de contexto ${ }^{79}$.

${ }^{78}$ Atria, Fernando, La soberania y lo politico, cit. (n. 18).

${ }^{79} \mathrm{~A}$ las mismas conclusiones se arriban en CARRÉ DE MALberg, Raymond, cit. (n. 1), pp. 1161 ss. 
Sin embargo, esta posición se enfrenta a la difícil tarea de explicar cuál es el rol que juega el reconocimiento constitucional del principio de la soberanía popular en los textos constitucionales.

La posición alternativa, que sostiene que la soberanía y el poder constituyente del pueblo tienen un rol jurídico que jugar, tiene ese dato a su favor. Sin embargo se expone a numerosos problemas de coherencia y, en general, no permite absolver las críticas que se han presentado más arriba, de la forma en que lo fueron.

En la siguiente sección se intentará revisar estas opciones a la luz de la tarea de determinar cuál es el sentido normativo que la disposición que reconoce la soberanía popular puede tener en el orden estatal vigente o, por el contrario, si no debe tener ninguna.

\section{LA SOBERANÍA POPULAR COMO PRINCIPIO CONSTITUCIONAL}

La palabra soberanía es usada en dos lugares diversos dentro de la Constitución Política con dos sentidos distintos. Es usada en el artículo 5 que analizaremos a continuación, pero también es usada en el artículo 22 inciso $2^{\circ}$ en los siguientes términos: "Los chilenos tienen el deber fundamental de honrar a la patria, de defender su soberania y de contribuir a preservar la seguridad nacional y los valores esenciales de la tradición chilena”.

La expresión “soberanía” en este inciso es usada como soberanía externa del Estado, en términos del Derecho internacional. Basta constatar que el uso en uno y otro caso, artículo 5 y artículo 22, hacen referencia a cuestiones distintas ${ }^{80}$.

\section{La soberanía en el artículo 5 de la Constitución Politica.}

El artículo 5 de la Constitución Politica establece la siguiente: "La soberania reside esencialmente en la Nación. Su ejercicio se realiza por el pueblo a través del plebiscito y de elecciones periódicas y, también, por las autoridades que esta Constitución establece. Ningún sector del pueblo ni individuo alguno puede atribuirse su ejercicio ${ }^{81}$. I El ejercicio de la soberania reconoce como limitación (n. 3).

${ }^{80}$ Sobre el concepto de soberanía externa puede consultarse KRIELE, Martin, cit.

${ }^{81}$ Existe una continuidad en la regulación constitucional de la soberanía, entre las Constituciones de 1833, 1925 y 1980. Los antecedentes de la norma vigente se remontan a la Constitución de 1833. Ésta señalaba en su artículo 4: "La soberanía reside esencialmente en la Nación, que delega su ejercicio en las autoridades que establece esta Constitución”. La Constitución de 1925 incorporó un artículo 2 a lo que hoy establece el artículo 5: Artículo 2: "La soberania reside esencialmente en la Nación, la cual delega su ejercicio en las autoridades que esta Constitución establece. Artículo 3: "Ninguna per- 
el respeto a los derechos esenciales que emanan de la naturaleza humana. Es deber de los órganos del Estado respetar y promover tales derechos, garantizados por esta Constitución, así como por los tratados internacionales ratificados por Chile y que se encuentren vigentes".

Del análisis de este artículo puede proponerse el siguiente programa para su análisis: $i$ ) sentido normativo de la disposición; ii) determinación del titular de la soberanía; iii) significado de la expresión "ejercicio" de la soberanía; y iv) límites de la soberanía. La interpretación que se llevará a cabo contrastará con la que, siguiendo a la Comisión de Estudios de la Nueva Constitución, la mayoría de la doctrina nacional ha presentado.

\section{La soberania en la doctrina nacional.}

En cuanto al sentido normativo de la disposición, la doctrina más autorizada, si bien concurre a afirmar que se consagra un modelo de soberanía nacional en desmedro del modelo de la soberanía popular, luego no tiene problemas en conceder que la soberanía es sinónimo de poder estatal ${ }^{82}$.

Ello lleva a reducir el sentido normativo de la disposición a un sinsentido: si la soberanía es sinónimo de poder estatal no puede ser el pueblo o la nación ni su titular ni quien la ejerce, el poder del Estado corresponde, como parecerá obvio, a los órganos del Estado. Parece haber un desajuste entre las explicación teórica y el reconocimiento constitucional de la soberanía nacional, incluso en los términos que la Constitución Política lo hace.

En cuanto al titular de la soberanía, la doctrina nacional se embarca en un análisis (no demasiado fértil en este caso) de las disputas y diferencias entre la teoría de la soberanía nacional y la teoría de la soberanía popular ${ }^{83}$.

En cuanto al ejercicio de la soberanía, la doctrina nacional considera que las formas de su ejercicio quedan establecidas por la Constitución Política. Puede ser interesante revisar la explicación de José Luis Cea en relación a este asunto. Para él, el ejercicio de la soberanía es realizado, como sostiene literalmente el artículo 5, por el pueblo mediante las elecciones periódicas

sona o reunión de personas pueden tomar el titulo o representación del pueblo, arrogarse sus derechos, ni hacer peticiones en su nombre. La infracción de este artículo es sedición". Los antecedentes que se tuvieron en vista para la redacción del artículo promulgado en 1980 fueron el artículo 5 del proyecto de la CENC y el artículo 5 del proyecto del Consejo de Estado. Su antecedente histórico puede encontrarse en el artículo 3 de la Declaración de los Derechos del Hombre y del Ciudadano.

${ }^{82}$ Cea Egaña, José Luis, Derecho constitucional chileno (Santiago, Ediciones Universidad Católica de Chile, 2008), pp. 207-211, Vivanco, Ángela, Curso de Derecho constitucional (Santiago, Ediciones de la Universidad Católica de Chile, 2004), pp. 9091.

${ }^{83}$ Cea Egaña, José Luis, cit. (n. 82), pp. 208-211, Molina, Hernán, Instituciones politicas (Santiago, LexisNexis, 2006), pp. 74-76, Vivanco, Ángela, cit. (n. 82), p. 91. 
y el plebiscito y por los órganos constitucionales. Ello parece fundarse en que el titular de la soberanía es la nación, que en palabras de Cea, "es una abstracción", por lo que, la soberanía es ejercida necesariamente por alguien distinto de su titular: por el pueblo, o más bien por una fracción de éste, por la ciudadanía. ¿Cómo se lleva a cabo ese ejercicio? Cea sostiene que de dos formas. Directamente por parte del electorado, mediante elecciones y plebiscito. Indirectamente mediante los órganos representativos del Estado. Finalmente, sostiene, sin mayor explicación, que la soberanía también la ejercen los órganos constitucionales no representativos, como los tribunales de justicia o los militares, "que actúan vía indirecta como representantes del soberano" 84 .

Finalmente, en cuanto a los límites, la doctrina nacional presenta variadas explicaciones en relación a la fundamentación de los derechos humanos o que arrancan de la naturaleza humana o en la dignidad de la persona o el Derecho natural, pero no se preocupa por elaborar una respuesta a la cuestión de cómo o por qué tales derechos limitan a la soberanía ${ }^{85}$.

Ante la falta de desarrollo del sentido normativo que la disposición del artículo $5^{\circ}$ tiene y la desconexión del análisis que por parte de la doctrina nacional recibe la teoría de la soberanía y el poder constituyente, no puede presentarse una elaboración dogmática-teórica de dicha disposición como un ejercicio de revisión y diálogo de la doctrina constitucional actual. El trabajo de análisis de la disposición del artículo 5 inciso $1^{\circ}$ que se realiza a continuación y su puesta en relación con la teoría expuesta más arriba carece, en este entendido, de un horizonte de referencia interpretativo y se presenta, entonces, como un ejercicio preliminar y crítico.

\section{El sentido normativo del articulo 5 y el poder constituyente del pueblo.}

Si puede descartarse el argumento que asimila la soberanía popular a la soberanía estatal, se llega a la encrucijada de tener que determinar cuál es el rol que cumple la consagración constitucional de la soberanía popular.

Existen dos elementos que hay que tomar en cuenta para esta tarea. En primer lugar, si el reconocimiento de la soberanía del pueblo implica el reconocimiento de la disponibilidad del orden estatal para el poder constituyente del pueblo, existen buenas razones para pensar que la Constitución no quiere hacerse consciente de su propia precariedad. Sin embargo, parece ineludible concluir también, que el artículo 5 de la Constitución Política sugiere cuál es el fundamento del orden estatal ${ }^{86}$. Para abordar este problema, sin caer

\footnotetext{
${ }^{84}$ Cea Egaña, José Luis, cit. (n. 82), pp. 211-212.

${ }^{85}$ Cea Egaña, José Luis, cit. (n. 82), pp. 213-214, Molina, Hernán, cit. (n. 83), p. 77, Vivanco, Ángela, cit. (n. 82), p. 93.

${ }^{86} \mathrm{El}$ mismo dilema puede encontrarse en García de ENTERría, Eduardo, La len-
} 
en el sinsentido de asimilar soberanía popular y soberanía estatal, se debe intentar conciliar o soslayar los problemas de compatibilidad de estos dos elementos.

Al incorporar el artículo 5, la Constitución reconoce, sin lugar a dudas, que el poder del Estado proviene, en última instancia, del pueblo. Esa es la base de cualquier explicación subsiguiente.

Sin embargo, no es claro que la Constitución quiera reconocer la forma en que dicho poder se imputa al pueblo, dado que se expone a la crítica de la precariedad. Esto ocurre si es que afirmar que la soberanía se sitúa en el pueblo implica a su vez: $i$ ) la idea de que el fundamento y validez de la Constitución está en la voluntad del pueblo de mantener la constitución (poder constituyente en latencia); y ii) la idea de que la soberanía implica el poder constituyente del pueblo y, de esta manera, reconoce implícitamente que el pueblo legítimamente puede volver a actuar soberanamente, suspender la constitución y ejercer el poder constituyente.

Existen dos estrategias, no contradictorias, que soslayan la precariedad. La primera, busca sostener, como Kriele, que la soberanía del pueblo no tiene lugar dentro del orden jurídico vigente pese a ser su origen necesario. La soberanía se extingue mediante el establecimiento de la Constitución. El reconocimiento de la soberanía popular en la constitución es una referencia al origen en que la constitución fundamenta su validez, pero no una reflexión sobre la precariedad de la constitución. Luego, la constitución no reconoce poder constituyente alguno, sino que hace una referencia a un poder que se extinguió en el momento mismo de su ejercicio.

Ya se señaló cuál era el problema de esa concepción. Ella no comprende que la soberanía justamente es tal porque no puede ser silenciada. Sin embargo, este planteamiento que es problemático en el plano de la teoría puede no serlo en el plano de la dogmática constitucional, especialmente considerando la prevención de que el Derecho no puede contemplar las circunstancias de su suspensión, sin erosionar su significado de tal manera que haga imposible su comprensión como Derecho. Es por eso que en el nivel de la dogmática, lo máximo que puede hacer la constitución es imputar su origen a una decisión del pueblo ${ }^{87}$.

gua de los derechos. La formación del Derecho público europeo tras la revolución francesa (Madrid, Alianza, 1994), pp. 102 ss.

${ }^{87}$ Una tesis más radical, que intenta no incurrir en la reflexión sobre la precariedad es la que propone Ramón Pusnet al sugerir que la conciliación entre soberanía y constitución puede se llevada a cabo mediante la comprensión del pueblo soberano como una abstracción creada por la propia constitución. Pusnet, Ramón, En el Estado constitucional hay soberano, en Fundamentos. Cuadernos monográficos de teoría del Estado, Derecho público e Historia constitucional, 1 (1998). 
La segunda afirmación reconoce en tal disposición un principio de justicia política que considera la igualdad de los ciudadanos de cara al fenómeno de la justificación del Estado: la soberanía no recae en cada uno de los miembros del pueblo sino en todos ellos en su conjunto. La atribución de la soberanía al pueblo va dirigida el rechazo de la posibilidad de que otro sujeto ejerza o se pueda atribuir la soberanía y, por ende, es un resguardo para la Constitución frente a intentos de una usurpación. García de Enterría sostiene al respecto: "El ejercicio de la autoridad [...] no puede ser realizado sino como “emanación” de la soberanía del pueblo, atribuido, pues, por éste y como “agente" o comisionado del mismo, sin que la soberanía como tal pueda pasar a ningún individuo, a ningún estamento o corporación. Con esta salvedad se está excluyendo de modo expreso la posibilidad de apropiación histórica, personal o estamental, del poder, que era lo que el Antiguo Régimen ofrecía a través de instituciones como la monarquía [...]"88.

Esta interpretación se ve apoyada en el argumento de que la constitución consagra un procedimiento para su propia modificación mediante la introducción de una potestad constituida de reforma de la constitución (artículos 127-129 CPol.), proveyéndola de las competencias materiales con las que cuenta el poder constituyente, pero exigiendo un procedimiento adecuado al orden constitucional.

\section{El titular de la soberanía y el concepto de pueblo en la Constitución.}

a) El pueblo constituyente y el pueblo constituido. En el inciso $1^{\circ}$ del artículo $5^{\circ}$ existen dos referencias distintas a la nación y al pueblo. Ellas deben ser entendidas de la siguiente manera. La referencia a la nación está hecha a la comunidad política titular de la soberanía ${ }^{89}$. En este caso, el uso de la expresión nación es equivalente a, e intercambiable con, la expresión pueblo, si se usa esta última como sinónimo de comunidad política. Si lo entendemos así, no hay problemas para encontrar reconocida la titularidad de la soberanía y del poder constituyente en el pueblo ${ }^{90}$.

${ }^{88}$ García de Enterría, Eduardo, cit. (n. 86), p. 103.

${ }^{89}$ Así lo comprende, por ejemplo, LASTARria, José Victorino, Elementos de Derecho público (1865), pp. 214-216.

${ }^{90}$ Desde un punto de vista histórico, pueden encontrarse dos antecedentes que determinaron la adopción de la palabra nación. El primero es el de la tradición de las constituciones anteriores de usar esa palabra. Como se puede observar de la comparación entre las disposiciones de las constituciones anteriores, de 1833 y de 1925, la fórmula de soberanía nacional no es nueva, proviene de la tradición constitucional chilena del siglo XIX El segundo es la explicación que puede encontrarse en la discusión de la Comisión de Estudios de la Nueva Constitución. En ella, la discusión terminológica giró en torno a la defensa de Jaime Guzmán sobre las inconveniencias del concepto de soberanía popular, por la identificación del pueblo con el proletariado, que parecía ser un 
En la segunda parte del inciso $1^{\circ}$ se hace referencia a que la soberanía es ejercida por el pueblo. Esta referencia podría presentar problemas sistemáticos para la interpretación de la nación como pueblo. Sin embargo, cuando se entiende que la expresión pueblo es susceptible de dos lecturas dentro de la Constitución, esa potencial objeción se diluye. El pueblo, como se señalara más arriba, es al mismo tiempo la comunidad política y el conjunto de individuos que la componen considerados separadamente. Es a estos últimos, considerados como conjunto de ciudadanos que participan en el gobierno del Estado, que esta disposición hace referencia. El pueblo considerado de esta forma, recibe de la constitución la atribución de participar en el gobierno estatal en conjunto con los órganos por ella establecidos. En este sentido, el pueblo se presenta como un poder constituido por la Constitución Política.

b) ¿Qué significa "esencialmente” ? Es quizás la expresión "esencialmente" la que contribuye de una manera más fuerte a afianzar la interpretación del artículo $5^{\circ}$. Qué algo pertenece esencialmente a la nación, significa que aquello no puede perderse. Inclusive ante el intento de arrebatarlo o llevar a cabo una suplantación, la soberanía no pertenecerá a otro que a la comunidad política.

Sin embargo, esto parece reafirmar la idea de que el pueblo conserva la soberanía y en cualquier momento puede decidir suspender el Derecho y ejercer el poder constituyente. El establecimiento del poder constituido no sería, por tanto, una cosa que implique el desasimiento del poder soberano o su traspaso a manos del Estado. La soberanía continúa en manos del pueblo y lo que se encuentra en manos de lo constituido (del pueblo en sentido agregativo y de los órganos que la Constitución establece) es otra cosa.

\section{Ejercicio de la soberanía.}

a) El pueblo ejerce el poder del Estado. La Constitución Política señala que el ejercicio de la soberanía se realiza por el pueblo y por las autoridades constitucionales. Esta disposición parece presentar el desafío interpretativo más importante para la interpretación que pretende encontrar una reflexividad de la constitución frente a la teoría de la soberanía popular y del poder constituyente del pueblo. ¿Cómo es posible que la soberanía, considerada como el poder de decidir sobre el Estado de excepción, y el poder constituyente, comprendido como el poder de establecer, mantener y cancelar una constitución, puedan ser ejercidos por los poderes constituidos?

Si hay que tomarse en serio la primera parte del inciso $1^{\circ}$ no puede leerse literalmente la segunda parte del mismo inciso. El poder constituyente no

inconveniente, teniendo en consideración el contexto social y político de la época. 
puede ser el poder constituido. Sobre esa base se erige la teoría misma del poder constituyente y se justifica, según la primera parte del inciso, la validez de la constitución misma y con la de ella, la de todo el orden jurídico.

Que la Constitución disponga que la soberanía se ejerce por el pueblo y por los otros órganos estatales tiene que significar, entonces, que el poder político del Estado, es decir, lo que es objeto de creación por parte del poder constituyente no es, en el Estado constitucional, ejercido directamente por la comunidad política, sino por los poderes constituidos. Sin embargo, como se señaló, que el poder del Estado no sea ejercido sólo por los órganos estatales sino también por el pueblo como poder constituido tiene un significado especial.

La Constitución Política ha reservado un lugar privilegiado para la posición del pueblo. Ello tiene su base en que, si bien el pueblo como comunidad política y el pueblo como poder constituido (como electorado y ciudadanía) no son lo mismo (y gran parte del argumento aquí planteado se basa en ello), tampoco son del todo separables. En la medida que el concepto del pueblo como comunidad política tiene base en la existencia real del pueblo, y allí se basa su fuerza política, la decisión de considerar al pueblo como quien ejerce el poder estatal dice relación con la decisión constitucional de consolidar un Estado democrático. Puede entenderse que las formas en que el pueblo participa del gobierno (elecciones y plebiscitos), al ser atribuidas al mismo titular de la soberanía, son una decisión constitucional a favor de conservar un rol preponderante en el gobierno del Estado.

b) Prohibición del ejercicio. La parte final del inciso $1^{\circ} \mathrm{del}$ artículo $5^{\circ}$ establece: "Ningún sector del pueblo ni individuo alguno puede atribuirse su ejercicio". ¿Cuál es su significado y cómo se relaciona con la interpretación del inciso hasta ahora realizada? Esta disposición es objeto de dos hipótesis interpretativas.

La primera hipótesis, que cae en el problema de la precariedad constitucional ante la soberanía, considera que la prohibición se dirige a proteger la soberanía de la nación. Si se entiende de esa manera, la Constitución estaría considerando, como criterio de legitimidad, el ejercicio de la soberanía por el pueblo como unidad política. Pero como es sabido que el pueblo no puede actuar inmediatamente, sino sólo a través de agentes, el sentido de la disposición se presenta como el criterio de reconocimiento de la actuación del pueblo: sólo allí donde la comunidad política entiende su actuar como un actuar propio, puede encontrarse el ejercicio de la soberanía. Sin embargo, al mismo tiempo que se establece como criterio de reconocimiento, incorpora un reproche a quienes atenten contra el orden estatal.

Esto puede explicarse, en la medida que se entiende que los actos de ejercicio de la soberanía son hechos brutos y no actos institucionales, y que es la 
lectura que la comunidad política hace de ellos, la que le atribuye un sentido institucional fundacional. En ese entendido, los actos que son juzgados por la prohibición de ejercicio de la soberanía pueden ser calificados como traición o usurpación o pueden ser calificados de actos fundacionales o soberanos. El criterio que la propia Constitución establece, para dicho juicio, es el de que dicha actuación la ejecute el pueblo como una unidad. Así, la Constitución Politica se hace reflexiva ante la contingencia de la política constitucional y establece algo como una regla de reconocimiento del ejercicio del poder constituyente del pueblo.

La segunda hipótesis, que rehúye la reflexividad, considera que la prohibición se dirige a proteger al ejercicio del poder constituido por los órganos del Estado y la ciudadanía. Así, la prohibición se dirige a expresar que todos los miembros del pueblo están sometidos a la constitución y no pueden ejercer otras atribuciones más allá de la que la misma constitución les atribuye. Si bien esta lectura es más acorde con el tenor literal de la disposición, entenderla como una simple prohibición, implica considerar que esta disposición tiene un contenido normativo idéntico a la disposición del artículo 7 inciso $2^{\circ}$, que establece: "Ninguna magistratura, ninguna persona ni grupo de personas pueden atribuirse, ni aun a pretexto de circunstancias extraordinarias, otra autoridad o derechos que los que expresamente se les hayan conferido en virtud de la Constitución o las leyes".

\section{Limites a la soberania,}

El problema de los límites de la soberanía, si bien no ha sido abordado expresamente, ha estado rondando la argumentación de todo este trabajo. La regulación que el artículo 5 inciso $2^{\circ}$ hace de esta cuestión, es compleja, y sobre ella ha recaído la mayoría del trabajo doctrinal y jurisprudencial que ha tratado la regulación constitucional de la soberanía. Es por esto que se soslayará el tratamiento detallado del tal disposición y se enfrentará sólo la cuestión de si la soberanía puede ser limitada y dependiendo de la respuesta que se dé a esa pregunta inicial, qué es lo que significa el encabezado del inciso $2^{\circ}$ del artículo 5 .

La pregunta sobre si la soberanía puede ser limitada es la pregunta con que la tradición de la doctrina de la soberanía se inauguró. La afirmación de la limitación de la soberanía es quizás la cuestión más paradójica de la doctrina de la soberanía del monarca. El monarca afirmaba su poder sin un límite en los buenos y antiguos derechos. Pero Bodin y los demás teóricos de la soberanía se esforzaron en encontrar un límite a la soberanía del monarca y lo encontraron principalmente en el Derecho natural. El reemplazo del Derecho natural por el discurso político de los derechos humanos ha llevado a que la natural reflexión para el reemplazo de la limitación de la soberanía 
pueda encontrarse en aquellos, considerando que se establece una relación de continuidad entre la doctrina de la soberanía del monarca y la soberanía popular.

¿Pueden los derechos humanos erigirse como un límite a la soberanía? Si el argumento de este artículo ha sido bien comprendido, la respuesta evidente debería ser no. Los derechos humanos no pueden ser un límite, porque la soberanía no está ni puede estar limitada. Una comunidad política que se quiere dar una constitución que no esté vinculada por los derechos humanos que emanan de la naturaleza humana, es libre políticamente para hacerlo.

Pero la tesis de la vinculación (de la soberanía por los derechos humanos) se enfrenta a dificultades adicionales. La siguiente pregunta, analíticamente anterior a la primera es ¿pueden los derechos humanos limitar algo? Si entendemos que los derechos humanos son los derechos que tienen los seres humanos sólo por el hecho de serlos, no existe criterio de reconocimiento alguno para tales derechos.

Tanto en el orden jurídico nacional como en el internacional, la positivización y el reemplazo de los derechos humanos por los derechos fundamentales y los derechos de los tratados internacionales tiene que ser considerado, desde el punto de vista de la limitación efectiva del poder del Estado, como necesario. Así, la disposición original del inciso $2^{\circ} \mathrm{del}$ artículo 5 incorporó una referencia a las normas constitucionales e internacionales que consagrarían tales derechos.

En este entendido, ¿qué significa que la soberanía esté limitada por los derechos que emanan de la naturaleza humana? La respuesta pasa, sin duda, por el alto valor que el discurso del liberalismo ha instalado en la limitación del poder del Estado. La comunidad se comprende como una comunidad con derechos y en ese sentido la identidad de la comunidad política expresa la decisión constitucional de establecer un límite. ¿Puede ese límite afectar la libertad de la comunidad de revocar esa decisión? La respuesta a esa pregunta es quizás el objeto de la disputa central del Derecho constitucional.

¿Cuál es el sentido que le corresponde por tanto al inciso segundo? La interpretación que se propone es la de entender que el inciso $2^{\circ}$ del artículo 5 consagra el principio de distribución entre el ámbito de la vida social que está disponible para ser afectado por actos y normas estatales y aquel ámbito de la vida social que debe estar inmune a dichas intervenciones según la decisión del poder constituyente. Esto es, la consagración del principio del Estado de Derecho ${ }^{91}$.

[Recibido el 31 de mayo y aprobado el 10 de septiembre de 2010].

\footnotetext{
${ }^{91}$ Véase: Marshall, Pablo, Notas sobre el Estado de Derecho y su consagración en la Constitución politica, en Revista Chilena de Derecho (en prensa, 2010).
} 


\section{BiBLIOGRAFÍA}

ATria, Fernando, El derecho y la contingencia de lo politico, en Derecho y Humanidades, 11 (2005).

Atria, Fernando, La soberanía y lo politico, en Derecho y Humanidades, 12 (2006).

Atria, Fernando, Legalismo, derechos y politica, en VV. AA., Derechos fundamentales Sela 2001 (Buenos Aires, Del Puerto, 2003).

Bermejo, José Luis, Origenes medievales en la idea de soberanía, en Revista de Estudios Politicos, 200-201 (1975).

Воввіо, Norberto, La teoría de las formas de gobierno en la historia del pensamiento político: Año académico 1975-1976 (México, Fondo de Cultura Económica, 2001).

Böckenförde, E. W., Estudios sobre el Estado de Derecho y la democracia (Madrid, Trotta, 2002).

Carré de Malberg, Raymond, Teoria general del Estado (México, Fondo de Cultura Económica, 1948).

Cea Egaña, José Luis, Derecho constitucional chileno (Santiago, Ediciones Universidad Católica de Chile, 2008).

Crossman, R. H. S., Biografía del Estado moderno (México, Fondo de Cultura Económica, 2000).

De Oтto, Ignacio, Derecho constitucional. Sistema de fuentes (Barcelona, Ariel, 1988).

Fioravanti, Mauricio, Estado y constitución, en Fioravanti, Mauricio (editor), El Estado moderno en Europa. Instituciones y Derecho (Madrid, Trotta, 2004).

GARCía DE ENTERría, Eduardo, La lengua de los derechos. La formación del Derecho público europeo tras la Revolución francesa (Madrid, Alianza, 1994).

Habermas, Jürgen, Facticidad y validez (Madrid, Trotta, 1998).

Hobbes, Thomas, Leviatan o la materia, forma y poder de una república, eclesiástica y civil (México, Fondo de Cultura Económica, 1980).

Jellinek, Georg, Teoría general del Estado (México, Fondo de Cultura Económica, 2000).

Kalyvas, Andreas, Soberanía popular, democracia y el poder constituyente, en Politica y Gobierno, 12 (2005).

Kelsen, Hans, Teoría general del Derecho y del Estado (México, Universidad Nacional Autónoma de México, 1969).

KRIELE, Martin, Introducción a la teoría del Estado: Fundamentos históricos de la legitimidad del Estado constitucional democrático (Buenos Aires, Depalma, 1980).

LASTARria, José Victorino, Elementos de Derecho público (1865).

Marshall, Pablo, Notas sobre el Estado de Derecho y su consagración en la constitución política, en Revista Chilena de Derecho (en prensa, 2010).

Molina, Hernán, Instituciones politicas (Santiago, LexisNexis, 2006).

Passerin D'Entrèves, Alessandro, La noción del Estado: Una introducción al teoría politica (Barcelona, Ariel, 2001).

Pusnet, Ramón, En el Estado constitucional hay soberano, en Fundamentos. Cuadernos monográficos de teoría del Estado, Derecho público e Historia constitucional, 1 (1998),

Rawls, John, El derecho de gentes (Barcelona, Paidós Ibérica, 2001).

Rousseau, Jean-Jacques, Contrato social (Madrid, Espasa Calpe, 1921). 
Schmitt, Carl, Teología politica 1, en Orestes Aguilar, Héctor (editor), Carl Schmitt, teólogo de la política (México, Fondo de Cultura Económica, 2001).

Schmitt, Carl, Teoría de la constitución (Madrid, Alianza, 1983).

SIEYÈs, Emmanuel-Joseph, Escritos politicos (México, Fondo de Cultura Económica, 1993).

Toceueville, Alexis de, El Antiguo régimen y la Revolución (México, Fondo de Cultura Económica, 1996).

VAREla Suanzes, Joaquín, Algunas reflexiones sobre la soberania popular en la constitución española, en Revista Española de Derecho Constitucional, 36 (1992).

Vivanco, Ángela, Curso de Derecho constitucional (Santiago, Ediciones de la Universidad Católica de Chile, 2004).

Wyduckel, Dieter, La soberanía en la Historia de la dogmática alemana, en Fundamentos, 1 (1998). 